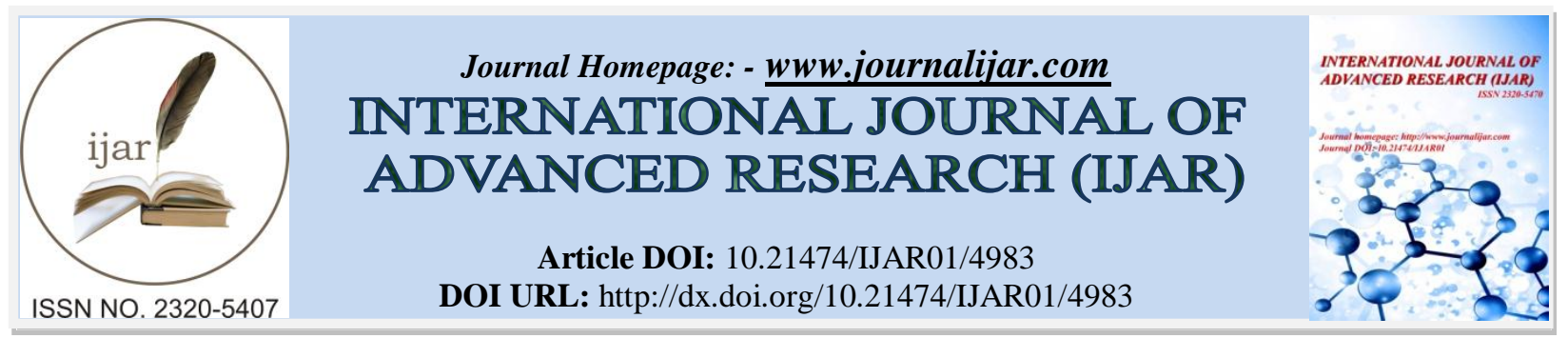

RESEARCH ARTICLE

\title{
CLINICAL STUDY OF POSTOPERATIVE WOUND INFECTION.
}

\section{Dr. K Ananth Prabhu ${ }^{1}$ And Dr. Balaji. P $^{2}$.}

1. Dissertation Submitted to the Yenepoya University of Health Sciences, Karnataka.

2. Department of general surgery yenepoya medical college and research institute, mangalore-575018.

\section{Manuscript Info}

Manuscript History

Received: 27 May 2017

Final Accepted: 29 June 2017

Published: July 2017

Key words:-

Surgical Wound Infection; Sepsis; Antibacterial Agents; Amikacin; Drug resistance, microbial.

\section{Abstract}

Background and Objective: Aim of this study was to

1. Study most common organisms encountered and their sensitivity and resistance to antibiotics in postoperative wound infection.

2. Study relation of emergency and elective surgery to postoperative wound infection.

3. Study efficacy of different modes of preoperative preparation on postoperative wound infection.

4. Study distribution of postoperative wound infection among different surgeries based on bacterial contamination such as clean, clean-contaminated, contaminated and dirty.

Methods: 210 cases of postoperative wound infection were analyzed. Appropriate history and examination was done. Culture and sensitivity reports were reviewed.

Results: Most common organism encountered is Pseudomonas (34.3\%) most sensitive antibiotic is amikacin (80\%) and most resistant antibiotics are Colistin (72.9\%). Postoperative wound infection was commonly encountered in emergency cases $(62.9 \%)$ and clean contaminated type of cases $(32.9 \%)$. Postoperative infection is most commonly found in patients prepared, by shaving (76\%), in $>24$ hours before surgery $(64.0 \%)$ and patients not taken preoperative bath $(77.3 \%)$.

Interpretation and Conclusion: Most common organism in post operative wound infection is Pseudomonas Most sensitive antibiotic is Amikacin and most resistant Colistin antibiotics are Postoperative wound infection is more in emergency case, clean contaminated type of cases and patients prepared, by shaving, in $>24$ hours before surgery and who have not taken bath.

Copy Right, IJAR, 2017,. All rights reserved.

\section{Introduction:-}

Surgical wound infections continue to consume a considerable portion of health care finance. Even though the complete elimination of wound infections is not possible, a reduction of the observed wound infection rate to a minimum level could have marked benefits in terms of both patient comfort and resources used.

These initial principles helped to change surgical therapy from a dreaded event, with infection and death commonplace, to one that alleviates suffering and prolongs life with predictable success when carefully performed. 
With the introduction of antibiotic therapy in the middle of the $20^{\mathrm{Th}}$ century a new adjunctive method to treat and prevent surgical infections was fostered. However, not only have postoperative wound and hospital-acquired infections continued, but widespread antibiotic therapy has not often made prevention and control of surgical infections more difficult. The present generation of surgeons has seen increasing numbers of serious infections related to a complex combination of factors, including the performance of more complicated and longer operations; an increase in the number of geriatric patients with accompanying chronic or debilitating diseases; many new surgical procedures with implants of foreign materials; a rapidly expanding number of organ transplants requiring the use of immunosuppressive agents; and increased use of diagnostic and treatment modalities that cause greater bacterial exposures or the suppression of normal host resistance.

The modern surgeon cannot escape the responsibility of dealing with infections and in dealing with them, of having the knowledge for the appropriate use of aseptic and antiseptic technique, proper use of prophylactic and therapeutic antibiotics, and adequate monitoring and support with novel surgical and pharmacologic as well as nonpharmacologic aids. Basic understanding of how the body defends itself against infection is essential to a rational application of surgical and other therapeutic principles to the control of infection.

\section{Objectives:-}

To study most common organisms encountered and their sensitivity and resistance to antibiotics in postoperative wound infection.

To study relation of emergency and elective surgery to postoperative wound infection

To study efficacy of different modes of preoperative preparation on postoperative wound infection

To study distribution of postoperative wound infection among different surgeries based on bacterial contamination such as clean, clean-contaminated, contaminated and dirty.

\section{Review of literature:- \\ Historical review:-}

Those who cannot remember the past are condemned to repeat it. - George Santayana, 1922.

Early in the history of man, there was recognition of the interplay between wounds, infection, and surgical manipulation. In fact, virtually all wounds became infected and infection was associated with high mortality. Wounds were treated by early physicians who were also surgeons. Treatment was based on trial and error and individual physician experience, yet many forms of effective therapy that varied for different cultures were discovered. In virtually every ancient society, the wound was viewed as a window into the body and an experimental laboratory for early physicians. Thus, the treatment of wounds led to formulation of medical dogma in each and every ancient culture.

The early Egyptians recognized some form of circulation of the blood based on the doctoring of wounds. In addition, some primitive remedies such as the use of pulverized malachite or honey in wounds may have been extremely effective, as noted by the modern day experiments of majno. The Greeks and Romans employed a variety of remedies that included the use of red wine, poultices of herbs, and other compounds that may have had antibacterial properties. They also were proponents of-laudable pusll, since infection was so common that it was considered the norm after wounding. These experiments were based on trial and error. Medical dogma arose solely from inferential data; for example, most disease processes were deemed to be an imbalance of various humors that consisted of either fire, water, air, or earth. It is of interest that the Chinese developed an explanatory system of medical dogma Extremely similar to the Greco-Roman one, the latter of which pervaded medicine for hundreds of years and was used as the basis of medical beliefs throughout Europe until the Renaissance.

More important for the development of modern surgery and the study of surgical infection was the occurrence of postmortem dissection wounds and deaths. Perhaps the most famous of these deaths is that of Dr Jakob Kolletschka, whose finger was pricked by an assistant during an autopsy. He died several days later, and his friend, Dr Ignaz Semmelweis, noted that this event was similar to the puerperal fever that he was studying in obstetrical wards. Determined to find the cause of his friend's death, semmelweis ascertained that medical students often transmitted what we now know to have been streptococcal infection to postpartum patients as they left the autopsy suite to perform deliveries. He thereby established the principles of antisepsis. 
The earliest discovery of a pathogenic microorganism was probably made by Augustino Bassi (1835), who showed that the muscardine disease of silk worms was caused by a fungus. Davaine and Pollender (1850) observed anthrax bacilli in the blood of animals dying of the disease. In fact, even before the microbial etiology of infections had been established, this was evident to some observant physicians.

The development of bacteriology as a scientific discipline dates from Louis Pasteur (1822-95). Though trained as a chemist, his studies on fermentation led him to take an interest in microorganisms. He established that fermentation was the result of microbial activity and that different types of fermentations were associated with the activity of different kinds of microorganisms (1857).

In the course of these studies, he introduced techniques of sterilization and developed the steam sterilizer, hot-air oven and autoclave. He also established the differing growth needs of different bacteria.

While Pasteur in France laid the foundations of microbiology, Robert Koch (1843-1910) in Germany perfected bacteriological techniques during his studies on the culture and character of the anthrax bacillus (1876). He introduced staining techniques and methods of obtaining bacteria in pure culture using solid media.

Peter JE Cruse and Rosemary Foord at the Foothills Hospital in Calgary, Alberta, Canada initiated one of the earliest and largest prospective studies of wound infections. In 1973 they reported on 23,469 wounds over a 5 year period and in 1980 reported on 62,939 wounds epidemiologic methodology, including 28 day outpatient follow up, and the demonstration of a decrease in the clean wound infection rate over the period of the study, thought to be secondary to the surveillance itself and the reporting of wound infection rates to the practicing surgeons.

\section{Definitions:-}

Although wounds that drain creamy pus are definitely infected and those that are closed and heal primarily are definitely not infected, an intermediate category of wounds may be considered -possiblyll or -probablyll infected. With the infection rate for clean wounds being inherently low, these indeterminate categories can comprise a significant proportion of wounds that are not clearly infected or uninfected and may skew data in any study of infection rates. Partly in order to address this problem of no uniform definitions, The Surgical Wound Infection Task Force, including representatives from the Society for Hospital Epidemiology of America, the Association for Practitioners in Infection Control, the Centers for Disease Control, and the Surgical Infection Society, published in 1992 definitions of surgical site infections. In addition, the term surgical wound was intentionally replaced with surgical site to include infections arising after surgery that were in organ spaces deep to the skin and soft tissue, such as the peritoneum and bone.

\section{Superficial Incision Surgical Site Infection:}

1. Purulent drainage from the superficial incision.

2. Organisms isolated from an aseptically obtained culture of fluid or tissue from the superficial incision.

3. At least one of the following signs or symptoms of infection: pain or tenderness, localized swelling, redness, or heat, and superficial incision is deliberately opened by surgeon, unless culture of incision is negative.

4. Diagnosis of superficial incisional surgical site infection by the surgeon or attending physician.

\section{Deep Incisional Surgical Site Infection:}

1. Purulent drainage from the deep incision but not from the organ/space component of the surgical site.

2. A deep incision spontaneously dehisces or is deliberately opened by a surgeon when the patient has at least one of the following signs or symptoms: fever $\left(>38^{0}\right)$, localized pain, or tenderness, unless culture of incision is negative.

3. An abscess or other evidence of infection involving the deep incision is found on direct examination, during reoperation or by histopathologic or radiologic examination.

4. Diagnosis of deep incisional surgical site infection by a surgeon or attending physician.

\section{Organ/Space Surgical Site Infection:}

1. Purulent drainage from a drain placed through a stab wound into the organ/space.

2. Organisms isolated from an aseptically obtained culture of fluid or tissue in the organ/space.

3. An abscess or other evidence of infection involving the organ/ space on direct examination, during reoperation, 
or by histo-pathologic or radiologic examination.

4. Diagnosis of an organ/space surgical site infection by a surgeon or attending physician.

A set of definitions was put forth in 1964 by the National Research Council, Ad Hoc Committee on Trauma, to help predict the probability of wound infection based on the degree of intraoperative bacterial contamination. These definitions, a modified version of which is given, have repeatedly been shown to have a strong association with wound infections.

1. Clean: Elective, primarily closed, no acute inflammation encountered, no entrance of normally or frequently colonized body cavities (Gastrointestinal, oropharyngeal, genitourinary, biliary, or Tracheobronchial tracts), and no break in sterile technique.

2. Clean contaminated: Nonelective case that is otherwise clean, controlled opening of a normally colonized body cavity, minimal spillage or break in sterile technique, reoperation through clean incision within 7 days, negative exploration through intact skin.

3. Contaminated: Acute nonpurulent inflammation encountered, major break in technique or spill from hollow organ, penetrating trauma less than 4 hours old, chronic open wounds for grafting.

4. Dirty: Purulence or abscess encountered or drained, preoperative perforation of colonized body cavity, penetrating trauma more than 4 hours old.

Although these definitions have proven very useful, there are clearly differences among wounds in each category. Regarding the use of antibiotics in clean cases, for example, breast surgery may benefit from the use of prophylactic antibiotics, whereas inguinal herniorrhaphy probably does not and the removal of a minor skin lesion certainly does not. It is hoped that in the future, with computerized data bases, studies of wound infections will be performed for specific procedures without having to resort to these broader, more generalized categories.

\section{Etiology:-}

Microorganisms' causing SSI can be either exogenous or endogenous. Exogenous microorganisms come from the operating team or from the environment around the surgical site (such as or, equipment, air, and water). Endogenous microorganisms come either from the bacteria present in the patient at the surgical site or from bacteria present at a different location (e.g., remote site infection, nasal colonization).

Pathogens in surgical infections:

Bacteria important in surgical infections are broadly divided into aerobic and facultative bacteria in one group and anaerobic bacteria in the other, into gram positive gram negative bacteria; and into bacilli (rods) and cocci.

Most infections presenting in surgical patients are caused by endogenous bacteria. Specific bacteria are found in specific parts of the body and the exposed anatomic areas during a surgical procedure are usually the source of microorganisms that cause infection. It is helpful to know the normal microbial flora of the body, since this helps direct prophylactic antibiotics, start intelligent empiric therapy, and suspect the origin of an unknown source of infection in patients with positive blood culture.

It is also helpful to be familiar with the different classification of bacteria since it can take up to 72 hours for a final culture to give the result as a specific bacteria; however, Gram stain and biochemical tests can help in providing earlier guidance regarding which group of bacteria may be responsible for an infection.

Gram Positive Cocci:

Gram positive cocci of importance to surgeons include staphylococci and streptococci. Staphylococci are divided into coagulase- positive and coagulase-negative strains. Coagulase-positive staphylococci are S. aureus and are the most common pathogen associated with infections in wounds and incisions not subject to endogenous contamination. Coagulase positive staphylococci should be assumed resistant to penicillin and require treatment by a penicillinase resistant antibiotic. 


\section{gram-negative rods (GNR):-}

A great variety of gram-negative rods are associated with surgical infections. Most fall into the family enterobacteriaceae. These are all facultative anaerobic bacteria and include the familiar genera Escherichia, Proteus, and Klebsiell. The three general (easy gram-negative rods) are considered together because they are relatively common in mixed surgical infections and because they are relatively sensitive to a broad variety of antibiotics, especially second-generation cephalosporins. Other common in surgical infections include Enterobacter, Morganella, Providencia, and Serratia. Gramnegative rods recovered from infections originating in the community, such as uncomplicated appendicitis or diverticulitis, are less likely to involve antibiotic resistant strains.

Obligate aerobic gram-negative rods that can be found in surgical infections include Pseudomona and Acineto bacter species. These organisms are most commonly found in hospital-associated pneumonias in surgical patients but may also be recovered from the peritoneal cavity or severe soft tissue infections.

Acinetobacter species are resistant to aztreonam resistant even to the most effective antibiotics, and patients with such pathogens are probably best treated empirically with two antibiotics until in vitro susceptibility testing becomes available.

Stenotropomonas maltopbilia (previously pseudomonas or Xanthomonas maltophilia) is uniformly resistant to imipenem and meropenem and is most commonly encountered as an emerging organism when one of these carbapenems is used for empiric treatment of a serious infection.

\section{Anaerobes:-}

Anaerobic bacteria are the most numerous inhabitants of the normal gastrointestinal tract, including the mouth. The most common anaerobic isolate from surgical infections is Bacterioides fragilis. B. fragilis and Bacteroides thetaiotamicron are two common anaerobic species with significant resistance to many $\beta$-lactam antibiotics.

Other anaerobic species commonly recovered from surgical infections but with less significant bacterial resistance patterns include bacteroides melaninogenicus and most of the anaerobic cocci.

The other important genus of anaerobic bacteria found in surgical infections is Clostridium, previously mentioned in the discussion of necrotizing soft tissue infections. Although they can survive for variable periods while exposed to oxygen, they require an anaerobic environment for growth and invasion and for elaboration of the toxins that account for their dramatic virulence in soft tissue infections. The Clostridium species are all gram-positive sporeforming rods. However, when present in human infections, they do not form spores, so gram positive rods without spores.

Clostridium difficile belongs to this family, and Clostridium tetani is responsible for tetanus.

The recovery of anaerobes from a soft tissue infection or even from the blood implies their growth and multiplication in a focus of dead tissue. The predominant source of anaerobic bacteria is the gastrointestinal tract; thus, an anaerobic infection implies a defect in the anatomic integrity of the gastrointestinal tract.

Fungi:

Fungi are infrequently the primary pathogens in deep seated surgical infections. Candida infections, however, have become a relatively frequent pathogen in surgical infection over the last years. The NNIS data show that it is now the fourth cause of bacteremia in hospitalized patients in the United States and other studies show that it can be present as the source of intra-abdominal infection in $8 \%$ of the Cases.

Candida species recovered from open wound usually represent contamination, not true invasion. Recovery of candida species from peptic ulcer perforations also does not usually require treatment.

Intra abdominal candida infections are more common in association with infections after severe pancreatitis. Fluconazole is usually an adequate treatment for C. albicans. However, 
Candida krusei, Candida glabrata, and occasionally candida lusitaniae, which are becoming more frequent in surgical infections, are species resistant to fluconazole, in which case the use of voriconazole or amphotericin is indicated.

Patient level factors affecting the incidence of wound infections:-

Following is a consideration of factors thought to affect the susceptibility of any wound to infection at the whole patient level; further, these have been divided into two categories: endogenous and exogenous. Endogenous refers to unique attributes of the patient which either may (e.g., obesity) or may not (e.g. age) be alterable prior to surgery. Exogenous refers to characteristics of the operative experience not unique to any patient which can frequently be influenced by the surgeon (e.g., length of operation).

\section{Endogenous factors:-}

Age:-

Extremes of age have long been thought to influence the likelihood of wound infections, perhaps owing to decreased immunocompetence. In 1971, Davidson et al described age, as well as duration of operation, wound class, bacterial contamination, and type of ward, as the critical determinants of wound infection. In a prospective study of 8474 patients, Mead et al demonstrated an increased clean wound infection rate in patients less than 1 year old $(2.7 \%)$ or greater than 50 years old $(2.8 \%)$, versus those 1 to 50 years old $(0.7 \%)$. Even in clean contaminated procedures, age has been associated with an increased infection rate, as in the 1988 study by Claesson and Holmlund in a relatively homogeneous population of patients undergoing elective colorectal procedures. This association remained valid even after multivariate analysis. Not all studies, however, have corroborated this finding. Gil-Egea et al studied 4468 clean wounds and found an infection rate of $3.4 \%$ in patients less than 65 years old and $2.7 \%$ in those 65 or older. Haley et al, using stepwise multiple logistic regression, did not find age to be an independent predictor of wound infection in 58,498 patients. Age, obviously, is an immutable patient characteristic and, even if it is a risk factor for wound infection, it appears to be at most a modest one.

\section{Pre-existing Illness:-}

It has been logically assumed that wound infections are more common among patients with multiple pre-existing diseases, although how to quantify this factor of generalized illness is unclear. During the 1970 Study on the Efficacy of Nosocomial Infection Control (SENIC) project, 58,498 patients undergoing operations, randomly selected from 338 hospitals, were studied for wound infection. Stepwise multiple logistic regression techniques identified four independent risk factors, one of which was three or more diagnoses at time of discharge (excluding those reflecting surgical wound infections and their complication). A risk index was developed, and this finding was verified in a 1975-1976 prospective study of 59,352 wounds. The SENIC risk index has recently been replaced by the American Society of Anesthesiologists (ASA) preoperative assessment score. This modified index was validated in 84,691 procedures in 44 hospitals from 1987 to 1990. The overall wound infection rate among patients with ASA scores of I or II was $1.9 \%$, whereas among patients with scores of III to V it was $4.3 \%$. Garibaldi et al have since confirmed the independent predictive power of the ASA score in another prospective study of 1852 surgical patients, in which the odds ratio of wound infection for ASA class III to V patients, compared with class I or II patients, was 4.2 (95\% confidence interval, 2.8 to 6.4). Whether or not newer, more comprehensive measures of patient physiologic status, such as Acute Physiologic Assessment and Chronic Health Evaluation (APACHE) II or III, will give more precise prediction of risk remains to be seen.

\section{Diabetes Mellitus:-}

Although the pathophysiology of impaired wound healing in diabetics is not completely understood, several studies seem to indicate that it is a significant risk factor for wound infection. In the original 5-year study by Cruse and Foord, the clean wound infection rate was 10.7:\% in diabetics, compared with an overall clean wound infection rate of $1.8 \%$. In a prospective study of wound infections in 1009 patients undergoing cardiac surgery, published by Nagachinta et al in 1987, multiple logistic regression analysis revealed an odds ratio of 2.6 (95\% confidence interval, 1.4 to 4.8) for diabetics versus nondiabetics. It is unclear whether these differences could be accounted for as part of an estimate of overall illness, such as the ASA score, or whether the tightness of control of blood glucose influences the infection rate in this patient population.

\section{Obesity:-}

Although intuitively a risk factor, obesity has not consistently been found to be related to wound infections. Cruse and Foord found a 13.5\% wound infection rate in obese individuals in their initial report of 18,090 patients from 
the Foothills Hospital study, but it is not clear whether this effect was independent of other diseases also associated with wound infections, such as diabetes mellitus. In their study of cardiac procedures, Nagachinta et al found obesity to be associated with sternal or mediastinal wound infection, independent of other risk factors (relative risk, 3.8; 95\% confidence interval, 1.9 to 7.5 ). Ehrenkranz, on the other hand, in 1981 studied a subset of 52 obese patients and compared them with a randomly chosen group of 52 obese patients and compared them with a randomly chosen group of 52 nonobese patients; there were 8 wound infections in each group. Obesity, therefore, may be only weakly associated with wound infections and then perhaps only in certain incisions, such as median sternotomy.

\section{Length of Preoperative Hospitalization:-}

It is commonly held that a longer duration of preoperative hospitalization is associated with wound infection, theoretically via colonization with multiply resistant organisms. Both 5-year and 10-year studies by Cruse and Foord appear to support this in the latter study, for example, patients hospitalized for 0 to 1 days a clean wound infection rate of $1.2 \%$, whereas those hospitalized for more than 2 weeks had a 3.4\% infection rate. Mead et al, using Cruse's epidemiologic techniques, also found a higher risk of wound infection in patients with prolonged preoperative hospitalization. None of these studies, however, considered likely co-morbid factors, including other medical illnesses. Indeed, in Garibaldi et al 1991 study of 1852 surgical patients, prolonged preoperative hospitalization was related to wound infection when studied by univariate analysis, with an odds ratio of 5.0(95\% confidence interval, 3.4 to 7.3); stepwise logistic regression analysis, however, revealed this factor not to be an independent predictor. Unfortunately, none of these studies attempted to correlate the length of preoperative hospitalization with either colonized skin flora or organisms grown from infected wounds. To date, therefore, the association between preoperative hospitalization and wound infection must be considered unproven.

\section{Abdominal Operations:-}

In the initial multiple regression analysis of data from the 58,498-patient SENIC project, abdominal site of operation was found to be the strongest predictor of wound infection, with a regression coefficient of 1.12. National Research Council wound classification was another independent variable; refuting the possibility the abdominal operations are prone to infection because they are more likely to be contaminated or dirty. These findings have yet to be confirmed, and it is interesting to note that in Culver et al modification of the SENIC risk index, which has a greater predictive power than the original, the site of operation is the one risk factor that has been completely deleted. In addition, although Garibaldi et al showed an association between lower abdominal incisions and wound infection by univariate analysis (relative risk, 2.0;95\% confidence interval, 1.2 to 3.1), the association was not seen after multiple logistic regression analysis. Few other studies have considered body site an important variable in wound infection.

\section{Malignancy:-}

The presence of malignancy and its attendant, although poorly understood, alteration in immune status has sometimes been considered a risk factor for wound infection. Several studies, however, have failed to show an independent correlation between the two. Lewis, for example, in a 1977 review of 444 gastric operations, found no independent association between malignancy and wound infection. In 1981, Ehren-Kranz found 10 clean wound infections among 596 patients with malignancy (1.7\%), a rate slightly lower than the $2.1 \%$ (89 of 4259 ) seen in the overall group. Finally, in Claesson and Holmlund's study of 190 patients undergoing colorectal operations, the wound infection rate among those with malignancy was $17 \%$, versus $4.5 \%$ for those without malignancy. Upon multivariate analysis, however, this difference was found to correlate significantly with age and therefore was not of independent value. It is interesting to note, given the abundant data supporting an Immunologically mediated association between blood transfusion and poor outcome from the resection of colorectal malignancies, that Claesson' and Holmlund's population might have been most expected to show a correlation between malignancy and wound infection. Malignancy therefore, cannot be considered an independent risk factor for wound sepsis.

\section{Remote Site Infections:-}

In 1976, Edwards studied 1865 patients and found an epidemiologic correlation between remote site infection and subsequent surgical wound infection. The greatest risk appeared to be with remote infection involving a medical device, such as an indwelling urinary catheter. Among the 1852 patients studied by Garibaldi et al, the presence of a distant infection was associated with an overall wound infection rate of $16 \%$, considerably greater than the $6.1 \%$ seen in patients without a distant infection (odds ratio, 2.8;95\% confidence interval, 1.5 to 5.3). Upon multiple regression analysis, however, this association was no longer valid. It is unclear from these data, however, whether preoperative treatment of the remote infection successfully reduced the subsequent risk to the wound. Given the current aggressiveness with which distant infections are sought and treated preoperatively, such as by routine 
urinalysis, it is doubtful whether this question will ever be fully answered. It seems prudent to continue to consider remote site infection a risk factor and to treat it appropriately prior to operation, if possible.

\section{Malnutrition:-}

In 1995, Rhoads and Alexander published a retrospective study of 102 surgical patients, 42 of whom were found to be hypoproteinemic (serum protein $<6.3 \mathrm{~g} / \mathrm{dL}$ ). The wound infection rate was $29 \%$ among the hypoproteinemic group, versus $15 \%$ for the 60 control patients. Cruse and Foord, similarly, found an increase in wound infection rate among the original 23,649 patients in the Foothills Hospital project, with an overall rate of $17 \%$ among patients considered malnourished, versus $4.8 \%$ for all patients combined. In 1985, Shukla et al reported on 365 surgical patients who were studied for nutritional/immunologic status via anthropometric measurements, measurement of serum albumin and absolute lymphocyte count, and delayed-type hypersensitivity skin testing. A poor nutritional status was associated with a wound infection rate of $17 \%$, versus $8.3 \%$ for patients who were thought to be in a good nutritional state. Gorse et al, in a 1989 study of several different nosocomial infections, also reported an association between wound infection and a nutritional index, calculated from the serum albumin, total lymphocyte count, and a history of weight loss. This index, however, was found to be significantly lower in the wound infection group only at the time of diagnosis and not preoperatively, making interpretation of these data difficult. None of these studies, it should be noted, controlled for other known patient variables. In 1009 patients, Nagachinta et al also found an association between a serum albumin less than $3.9 \mathrm{~g} / \mathrm{dL}$ and wound infection, with a relative odds ratio of 2.4 (95\% confidence interval, 1.2 to 5.0 ).

Multiple regression analysis, however, failed to show any independent prognostic value for decreased serum albumin. Finally, Ehrenkranz found no significant difference in clean wound infection rates between patients with serum albumin greater than $3.4,2.8$ to 3.4, or less than $2.8 \mathrm{mg} / \mathrm{dL}$. Further studies with more precise measures of malnutrition and correction for co-morbid variables are needed before an independent association between malnutrition and wound infection can be proven.

\section{Cigarette Smoking:-}

The effect of cigarette smoking on wound infection rates has, surprisingly, not been well studied. Current cigarette smoking, however, was found by Nagachinta et al to be associated with a slightly increased sternal wound infection rate among patients undergoing cardiac surgery, even after multiple logistic regression analysis, with a relative odds ratio of 1.8 (95\% confidence interval, 1.1 to 3.1). Although the data are sparse, the concept of cigarette smoking as a risk for wound infection should be heeded because it is a potentially alterable behavior in the preoperative period.

\section{Exogenous factors:-}

Length of Operation:-

Risk of wound infection has repeatedly been shown to be proportional to the length of the operative procedure. At both 5 and 10 years of the Foothills Hospital study, Cruse and Foord found an increase in wound infections with longer procedures, roughly doubling with every hour of the procedure. Cases lasting 1 hour or less had a wound infection rate of $1.3 \%$, whereas those lasting 3 hours or more had a rate close to 4\%. Among the 1852 patients studied by Garibaldi et al, stepwise logistic regression analysis revealed an operative duration of greater than 2 hours to be associated with more wound infections. Procedures lasting more than 2 hours had a wound infection rate of $14 \%$, compared with $3.3 \%$ for those lasting less than 2 hours (relative risk, 4.6 ; $95 \%$ confidence interval, 3.1 to 4.6 ). These results are even more notable because wound class and intraoperative bacterial contamination were independent predictors of infection as well. Haley et al, from the first 58,498 patients of the original SENIC report, also found duration of operation of greater than 2 hours to be the second greatest independent predictor of risk after multivariate analysis, with a regression coefficient of 1.04. It is unclear from these studies, however, how frequently a prolonged duration of operation was secondary to a case's inherent complexity versus simpler case taking an unusually long time to complete. This question is partly addressed by Culvenet al's 1991 modification of the SENIC index.

Rather than taking an arbitrary time (e.g., 2 hours) over which an operation was designated prolonged, he considered a procedure lengthy of its length fell above the $75^{\text {th }}$ percentile for other similar procedures. Therefore, an appendectomy was considered prolonged if it lasted more than 1 hour, whereas coronary artery bypass grafting was not prolonged unless it required more than 5 hours. Using this index, operative time was still one of the variables, along with wound class and ASA class, that independently predicted infection. Prolongation of an operation, whether from an unusually complicated procedure, increased likelihood of normal wound contamination, 
or lapses in antibiotic coverage, must be considered a significant risk factor for wound infection.

\section{Glove Punctures:-}

Intuitively, punctures in the surgeon's gloves should predispose patients to wound infections. Garibaldi et al, studying 1812 wounds, did find by univariate analysis an increased wound infection rate with punctures, with an odds ratio of 3.1 (95\% confidence interval, 2.1 to 4.6). This relationship, however, did not hold up upon multivariate analysis. Cruse and Foord, studying the gloves with an electronic tester from the surgeons of 1209 patients, found 141 to be punctured. Amazingly, not a single wound infection occurred in those patients. White et al in a 1991 study of 188 patients undergoing cholecystectomy, found no correlation between the presence of glove punctures or tears and the number of incisional bacteria or the occurrence of wound infections. Most likely, the preoperative surgical scrub by the surgeon is usually adequate to prevent significant contamination from punctured gloves.

\section{Emergency procedures:-}

Several studies have shown emergency operations to be particularly prone to wound infections. Of the 4465 wounds studied by Gil-Egea et al 34,623 were made under emergent situations, and the wound infection rate for these was $5.1 \%$, versus the 3842 elective wounds with an infection rate of $2.9 \%$. Garibaldi et al reported a wound infection odds ratio of $7.6(95 \%$ confidence interval, 3.2 to 18.2) for emergency versus elective operations, but after multivariate analysis, this factor was no longer significant. At this time, emergency operations do not by themselves clearly predispose to wound infection.

\section{Time of Day:-}

In their initial study of 23,649 wounds, Cruse and Foord found that the clean wound infection rate more than tripled, to $6.8 \%$, for cases done between midnight and $8 \mathrm{AM}$, and that the clean contaminated wound infection rate doubled to $18.3 \%$ during the same period. These rates do not account for other factors, such as underlying patient illness, and are therefore difficult to interpret.

\section{Month of Year:-}

It remains unclear why a consistent rise in wound infection rate appears in the early summer, but Mead et al clearly demonstrated this phenomenon in their study of 8474 wounds over an 18-month period. These findings are similar to those found by Cruse and Foord for both clean and non-clean wounds, with a peak clean infection rate of almost $2 \%$ in July of 1977, the last year of the 10-year study, versus less than 1\% for most of the rest of the year. Condon et al, in a 5-year study of wounds at the Wood Veterans Administration Hospital, also noted peaks in wound infection rates in July. Whether this weak risk factor is the result of new surgical staff, changes in weather and personal hygiene, or other factors is not known.

\section{Airborne Contamination:-}

With the exception of rare epidemics traced to either air handling or surgical staff, airborne contamination of wounds in general surgery appears to play a small role in the pathogenesis of wound infections. Whyte et al studied 188 cholecystectomies and found that although the bacterial concentration on drapes distant from the wound depended on airborne bacteria, the bacterial counts from the wound and from the drapes close to the wound depended much more on bactibilia or skin flora. In fact, more bacteria were thought to have transferred from the wound to the drapes than vice versa. These results are in contrast to studies of open joint procedures, in which $98 \%$ of the bacteria found in wounds by Whyte et al were thought to be from the air, and the use of ultraclean operating rooms, as described by Lidwell et al, decreased the rate of joint infection by approximately $25 \%$.

\section{Wound level factors affecting the incidence of wound infections:- Wound Class:-}

The wound classification system proposed by the National Research Council in 1964 continues to be useful 30 years later. In 1980, the 62,939-wound Foothills Hospital project generated a set of wound infection rates for the four wound classes (clean 1.5\%, clean contaminated $7.7 \%$, contaminated $15.2 \%$, and dirty $40 \%$ )which other studies continue to use as a reference. More importantly, wound class has been shown to be independently predictive of wound infection in several large studies using multivariate analysis. In the original SENIC study in 1985, Haley et al demonstrated a contaminated or dirty wound to predict infection with a regression coefficient of 1.04 In Culver et al modification of the SENIC risk index published in 1991, wound classification was the only risk factor unchanged from the original index. In Garibaldi et al study of 1852 patients, surgical wound class was once again found on stepwise logistic regression analysis to be predictive of wound infection with an odds ratio for contaminated or dirty 
wounds of 2.7 (95\% confidence interval, 1.9 to 4.6). These findings are more impressive because the finding of bacterial wound contamination, demonstrated by the growth of 30 or more colony-forming units (CFU) of bacteria from a Millipore filter pressed against the wound margin, was also independently predictive of infection in this study.

\section{Wound Contamination:-}

Wound contamination, as demonstrated by intraoperative culture, has been shown to be associated with later wound infection. Whyte et al showed that during cholecystectomy the number and species of bacteria cultured from the bile were predictive of wound contamination by culture and later wound infection. Later, Garibaldi et al, in 1991, found that 30 or more $\mathrm{CFU}$ of bacteria cultured from the wound were, by stepwise logistic regression, predictive of wound infection (odds ratio, 3.0;95\% confidence interval, 2.0 to 4.6), independent of wound class. In the prospective study of 190 patients undergoing elective colorectal surgery by Claesson and Holmlund in which all wounds were theoretically classified as clean contaminated, multivariate analysis revealed that 5 or more $\mathrm{CFU} / \mathrm{ml}$ of bacteria in peritoneal fluid were predictive of wound infection (infection rate without contamination, 6.4\%; with contamination, $41.2 \%$ ). How and if the routine culture of wounds should be incorporated into normal clinical practice is unclear, although any further studies of wound infections ought to include this important variable.

\section{Preoperative Hair Removal:-}

The shaving of hair from the operative site was, until recently, almost universal. Seropian and Reynold, in 1971, reported a wound infection rate of 5.6\% after razor shaving, $0.6 \%$ after depilatory use, and $0.6 \%$ after no hair removal. In 1983, Alexander et al reported on 1013 patients randomized to shaving or clipping on the evening before or the morning of operation. Thirty day wound infection rates were as follows: evening razor, $8.8 \%$; evening clipper, 10\%; morning clipper group and all other groups was significant. Currently, if hair removal is necessary, the use of a depilatory or clipper just prior to operation is the preferred method.

\section{Adhesive Drape:-}

The benefits of plastic adhesive and drapes remain controversial. Cruse and Foord ${ }^{8}$ found no benefit to the use of plastic adhesive drapes, with an overall infection rate of $1.5 \%$ in wounds draped in the standard manner and $2.4 \%$ in wounds protected with plastic drapes. In 1985, however, Alexander et al reported on the effective skin preparation consisting of a 1-minute alcohol application followed by the application of iodine-impregnated plastic adhesive drapes. Currently, any benefit to the use of plastic drapes appears to be small.

\section{Wound Irrigation:-}

The irrigation of wounds with antibiotic-containing solutions has a long history, starting with the use of topical sulfonamides in wounds in the 1930s. Several later studies appeared to show a benefit to wound irrigation, particularly in clean contaminated or contaminated procedures. For example, in a prospective study of 240 patients undergoing colon operations published in 1972 by Andersen et al the infection rate for patients receiving topical ampicillin was $2.5 \%$, versus $18.3 \%$ in wounds not irrigated. This benefit, however, was found only in patients not receiving intestinal antiseptics, which appeared to be more effective antibiotics for prophylactic use in clean contaminated and contaminated procedure, the added benefit of topical antibiotics is probably minimal in all but the most severely contaminated wounds. In clean wounds, in which the wound infection rate is already low, topical antibiotic irrigation is probably of no benefit, although its low cost and minimal morbidity assure its continued use.

\section{Tissue level factors affecting the incidence of wound infections:- Tissue perfusion:-}

Perfusion of a wound is critical to healing for several reasons, the two most important probably being delivery of oxygen and neutrophils, two essential and interrelated elements of normal wound healing. Owing to the inevitable 50 to $100 \mathrm{~mm}$ of poorly perfused adjacent tissue, the normal wound environment has a Po 2 of 5 to $10 \mathrm{~mm} \mathrm{Hg}$, a Pco2 of 50 to $60 \mathrm{~mm} \mathrm{Hg}$, and a pH of 6.5 to 6.9. In vitro studies have demonstrated a decrease in neutrophil killing and response to chemoattractants under these conditions. Further, Knighton et al demonstrated in vivo studies a 5 $\log$ reduction in wound fluid bacteria counts at 14 days simply by increasing the inspired Fio 2 of room air from $20 \%$ to $45 \%$. This effect was later noted to be further enhanced by the administration of systemic antibiotics. The deleterious effects of the presence of a wound foreign body are also explained by decreased oxygen tension, as Silver demonstrated in 1978 that the microenvironment immediately adjacent to a foreign body has a po 2 close to 0 $\mathrm{mm} \mathrm{Hg}$. It must be noted, however, that clinical experiments to support the use of hyperoxia to aid wound healing have yet to be completed. Meanwhile, it is axiomatic that wounds do not heal in the presence of severe vascular 
occlusive disease.

Local Immune Response:-

Only in the past 10 years have the tools become available to study the systemic and local immune response at a cell and cell mediator level. The keratinocyte has been shown to be an immunologically active cell able to produce and express a wide spectrum of immune response mediators, including intercellular adhesion molecule- 1 interleukin (IL)-1, tumor necrosis factor- $\alpha$. The effect of the presence of bacteria on all of these responses is unknown, but it is hoped that manipulation of these events will decrease the likelihood of wound sepsis. It is further interesting to note that, although the uninfected fetal wound has been demonstrated to heal by a process closer to regeneration than scar deposition, Frantz et al have shown that the presence of bacteria in fetal wounds induces a more adult-like collagen deposition, fibroplasias, and neovascularization. These findings raise the question of the role of bacteria or their products even in normal, uninfected adult.

\section{Physiology Of Wound Healing:-}

Inflammatory Phase: This phase represents the tissue's attempt to limit damage by stopping the bleeding, sealing the surface of wound and removing any necrotic tissue, foreign debris, bacteria present.
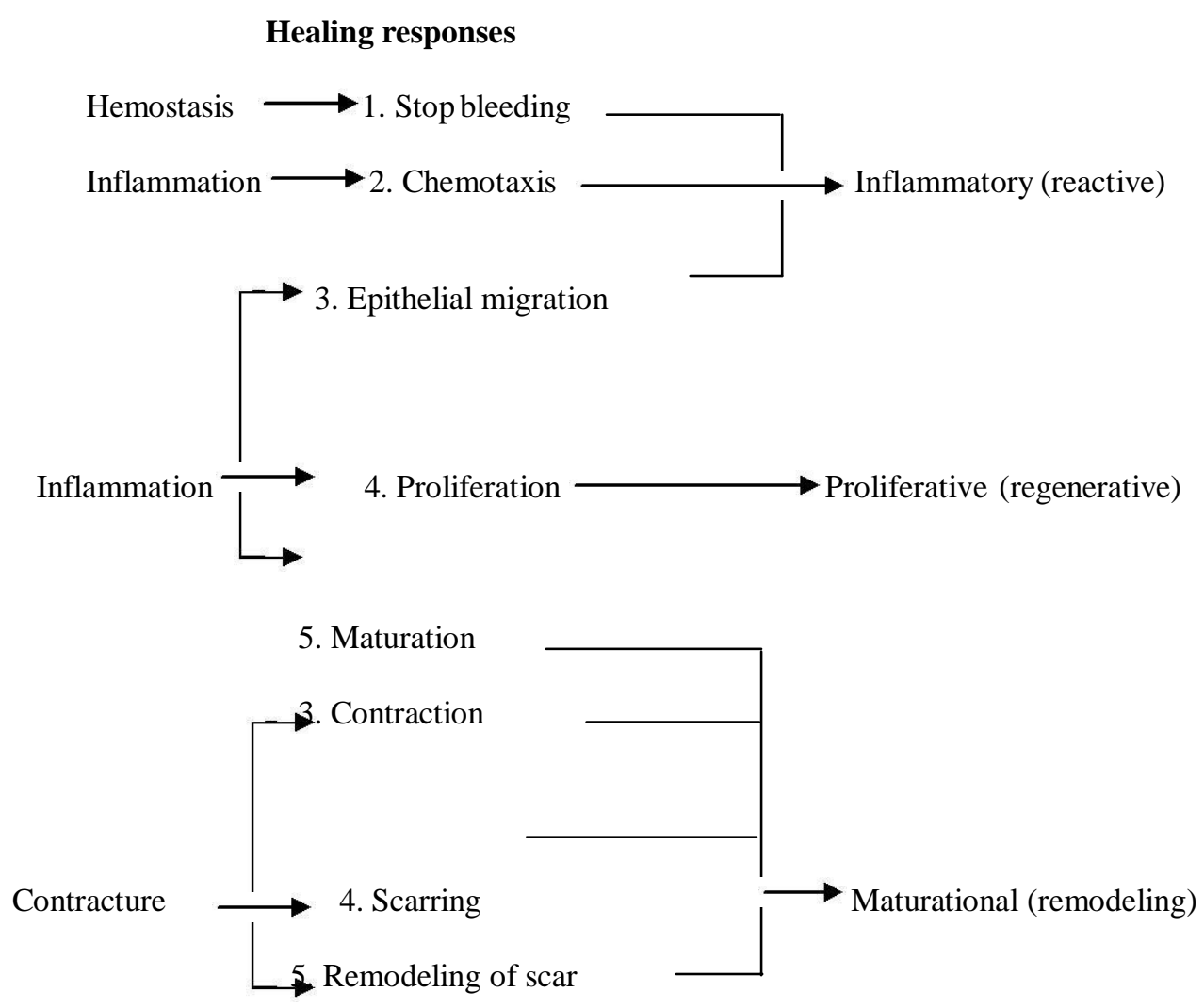

Schematic diagram of the wound healing continuum

a. Hemostasis and inflammation: Cessation of hemorrhage is aided by plugging of capillaries with erythrocytes and platelets

i) Increased vascular permeability: Binding results in changes in platelet conformation, triggering intracellular signal transduction pathways that result in platelet activation and release of biologically active proteins. Mast cells adherent to endothelial surface release histamine and serotonin, affecting the permeability of endothelial cells and causing leakage of plasma from intravascular space to the extracellular compartment.

ii) Polymorphonuclear cells: The chemotactic agent mediates the PMN response through signal transduction, as the chemotaxin binds to receptors on the cell surfaces. PMN do not survive longer than 24 hours. After 24 to 48 hours, the predominance of cells in the wound cleft shifts to mononuclear cells. 
iii) Macrophages: Macrophage is one ell that is truly central to wound healing. Wound macrophages release proteinases including matrix metallo proteinases, which degrade the ECM and are crucial for removing foreign material, promoting cell movement through tissue spaces and regulating ECM turnover. Macrophages secrete numerous cytokines and growth factors.

iv) Lymphocytes: Lymphocytes exert most of their effects on fibroblasts by producing stimulatory cytokines, such as IL-2 and fibroblast activating factor and inhibitory ones, such as TGF- $\beta$, TNF- $\alpha$ and IFN- $\gamma$.

B. Proliferative phase: This stage is characterized by the formation of granulation tissue, consisting of capillary bed, fibroblasts, macrophages, a loose arrangement of collagen, fibronectin and hyaluronic acid.

a. Angiogenesis: Capillary tube formation is a complex process involving cell-cell and cell-matrix interactions, modulated by adhesion molecules on endothelial cell surfaces. PECAM-1 has been observed to mediate cell-cell contact, whereas $\beta 1$ integrin receptors may aid in stabilizing these contacts and forming tight junctions between endothelial cells.

b. Fibroplasia: Fibroblasts are specialized cells that differentiate from resting mesenchymal cells in connective tissue, they do not arrive in the wound cleft by

diapedesis from circulating cells. The primary function of fibroblasts is to synthesize collagen that they begin to produce during the cellular phase of inflammation.

c. Epithelialization: Epithelialization involves a sequence of changes in wound keratinocytes, detachment, migration, proliferation, differentiation and stratification. Epidermal cells express integrin receptors that allow them to interact with ECM proteins, such as fibronectin. After the wound is completely re- epithelialized, the cells become columnar and stratified again, while firmly attaching to the re-established basement membrane and underlying dermis.

d. Extracellular matrix: Cells within it produce the macromolecular consistents including -

1. Glycosaminoglycans, polysaccharides chain, usually found covalently linked to protein in the form of proteoglycans and

2. Fibrous proteins such as collagen, elastin, fibronectin and laminin. The provisional matrix is a scaffold for cellular migration composed of fibrin, fibrinogen, fibronectin and vitronectin. GAGs and proteoglycans are synthesized next, supporting further matrix deposition and remodeling.

e. Collagen structure: The proline and glycine - rich collagen molecule is a long, stiff, triple stranded helical structure and comprises three collagen polypeptide and chains wound around one another is a rope like superhelix. There are at least 20 types of collagen, the main constituents of connective tissue are types I, II, III, $\mathrm{V}$ and XI.

Collagen synthesis: Collagen polypeptide chains are synthesized on membrane bound ribosomes and enter the endoplasmic reticular lumen as proalpha chains. These precursors have amino-terminal signal peptides to direct them to the ER as well as propeptides at both $\mathrm{N}$ and $\mathrm{C}$ terminal ends. Within the lumen of the ER, some of the prolines and lysines undergo hydroxylation, forming hydroxyproline and hydroxylysine. Hydroxylation results in the stable triple stranded helix through the formatin of interchain hydrogen bonds. After secretion in ECM, specific proteases clears the propeptides of procollagen molecules, forming collagen monomers. These monomers assemble to form collagen fiber's in the ECM, driven by collagen's tendency to self assemble.

f. Elastic fibers: Elastin fibers are predominantly composed of elastin, a highly hydrophobic protein. Elastin is composed of hydrophobic and alanine and lysine rich $\alpha$-helical segment that alternate along the polypeptide chain. The hydrophobic segments are responsible for the molecules elastic properties. Elastic fibrous consists of an elastin core covered with a sheath of microfibrils, which are composed of several distinct glycoproteins, such as fibrillin.

g. Glycosaminoglycons and proteoglycons - GAGs are unbranched polysaccharide chains composed of repeating disaccharide units, a sulfated amino sugar and uronic acid. Four types of GAGs exist -

1) Hyaluronan

2) Chondroitin sulfate and dermatan sulfate

3) Heparan sulfate

4) Keratan sulfate Hyaluronan is the simplest of the GAGs. Its abundance in fetal wounds is believed to be a factor in the scarless wound healing seen in fetal tissues. 
Basal lamina - Basal lamina are flexible, thin mats of specialized ECM that separate cells and epithelia from the underlying and surrounding connective tissue. In skin, the basal lamina is tether to the underlying connective tissue by specialized anchoring fibrils. This composite of basal lamina and collagen is the basement membrane.

Degradation of ECM - In injury or infection, a localized degradation of the ECM occurs so that cells can migrate across the basal lamina to reach the site of injury or infection. Locally secreted cellular proteases, such as MMPs or serine proteases, degrade the ECM components.

Maturational phase: Wound contraction is a centripetal movement of the whole thickness of the surrounding skin, reducing the amount of disorganized scar. Wound contraction appears to occur by a complex interaction of extracellular materials and the fibroblasts, which is not completely understood. Numerous studies have shown that fibroblasts in contracting wound undergo change to stimulated cells, referred to as myofibroblasts. These cells have both function and structures in common with fibroblasts and smooth muscle cells and express alpha smooth muscle actin in bundles called stress fibers. It appears that the stimulated fibroblasts develops a contractile ability related to formation of cytoplasmic actin- myosin complexes.

\section{Remodeling:-}

The fibroblast population decreases and the dense capillary network regresses. Wound strength increases rapidly within 1 to 6 weeks and then appears to plateau up to 1 year after the injury. Compared with unwounded skin, the tensile strength is only $30 \%$ in the scar. There is an increase in breathing strength after approximately 21 days, which is mostly a result of cross linking. Unlike normal skin the epidermodermal interface in the healed wound is devoid of rete pegs, the undulating projections of epidermis that penetrate into the papillary dermis. Loss of this anchorage results in increased fragility and predisposes the neoepidermis to avulsion after minor trauma.

\section{Wound healing processes affected by bacteria:-}

Most individuals expect that healing is an inevitable outcome; wound healing is taken for granted. However, although healing is perceived as inevitable, it can in fact be fraught with problems and altered at many points. If one debrides the wound of nonviable tissue and repairs it in a physiologic manner, the normal phases of wound healingreaction, regeneration, and remodeling -should proceed without difficulty. However, bacteria and bacterial products (e.g., endotoxins, metalloproteinases) can cause disturbances of this orderly scheme and affect each of the processes of healing. The modifying effect of inflammation on wound healing was noted by Hippocrates, and Careel and Hartmann reported the repair was arrested when an abscess far removed from the site of healing case cause a delay in the healing process. Each of the processes bacteria appears to be like the yin-yang effect of pharmaceutical agents. Low levels of bacteria seem to accentuate some processes such as difroplasia, whereas higher tissue bacterial levels severely inhibit the process. Modulation of the individual processes, when added together, results in demonstrable clinical effects.

\section{Infection: An imbalance of bacteria and host resistance:-}

Infection in clinical surgical practice has been defined as the product of the entrance, growth, metabolic activities, and resultant pathophysiologic effects of microorganisms in the tissues of the patient. Because man's biologic state is not germ- free even in the absence of clinical infection, a delicate balance must exist that allows him to survive in the presence of a great many species of bacteria, all with the potential to cause infection. This balance is an equilibrium between the factors of host resistance and the actions of the bacteria when no infection is present. If the equilibrium remains stable, host resistance factors eventually overcome any contamination of the wound. Once the equilibrium is upset, either by an impairment in the host defense mechanisms or by an increase in the bacterial inoculum, clinical infection may result.

A major advance in the prevention and management of wound infection has been the understanding that the mere presence of organisms in a wound is less important than the level of bacterial growth. A wealth of clinical and experimental data has shown that a level of bacterial growth of greater than 100,000 organisms per gram of tissue is necessary to cause wound infection and the potential for invasive sepsis for most species of bacterial.

Although the concept that the numerical level of bacteria is of clinical importance for determining soft tissue and wound infection was suggestedby French Army surgeons during World War I, the emphasis on wound bacterial levels disappeared following the war as attention shifted to the development of specific antimicrobials. Thirty to 40 years later, several unrelated observations reestablished the significance of bacterial numbers. Elek demonstrated 
that it requires an average of

$7.5 \times 10^{6}$ staphylococci to produce a pustule in normal human skin and that this number could be reduced 10,000 fold in the presence of a single silk suture. Kass reported a quantitative relationship between bacteria in urine and symptoms. Patients with pyelonephritis had greater than 100,000 organisms per milliliter of urine. If fewer than 100,000 organisms per milliliter were present, asymptomatic bacteria existed. Liedburg et al found that skin grafts were destroyed on rabbits when applied to beds inoculated with bacteria in concentrations greater than $10^{5}$, or 100,000 organisms per milliliter.

Further evidence of a critical tissue level of bacteria above which infection occurs has been demonstrated in various situations. Lindsey et al found that goats whose experimental wounds were inoculated with Clostridium died when the clostridia level reached 10 organisms per milliliter. Bendy et al showed that significant healing of decubitus ulcers occurred only when bacterial counts were less than $10 \% / \mathrm{mL}$. They found that despite the healthy appearance of a wound, healing did not occur if the bacterial level was greater than $10 \% / \mathrm{mL}$. Many studies from the United States Army Institute of Surgical Research have made invasive burn wound sepsis synonymous with a bacterial level of greater than $10^{5}$ organisms per gram of tissue.

Just as Liedburg had demonstrated for experimental skin graft, Krizek et al demonstrated the quantitative relationship between bacteria and skin graft survival in humans. In 50 granulating wounds, they performed quantitative bacterial cultures while preparing the wounds for grafting. Although all wounds are grafted purely on clinical grounds, when the bacterial counts were reviewed, the average graft survival was found to be $94 \%$ when the bacterial count was $10^{5}$ or fewer bacteria per gram of tissue and only $19 \%$ when the bacterial count was greater than $10^{5}$

Similar data have been reported for wounds undergoing delayed closure. In these wounds, various topical antibacterial creams were evaluated for controlling bacteria in the wounds. The evaluation was performed using quantitative bacterial tissue cultures. The wounds were closed on clinical criteria alone, without knowledge of the bacterial counts. In the initial study, there were 40 wounds. Review of the bacterial counts performed at the time of delayed wound closure revealed that 28 of

30 founds that contained 10 or fewer bacteria per gram of tissue progressed to uncomplicated healing, whereas non of the 10 wound closures performed on wounds with greater than $10^{5}$ organisms per gramof tissue were successful. This study was followed by one using quantitative bacteriology in a prospective manner. In that study, it was found that 89 of 93 wounds closed when the bacterial count was $10^{5}$ or fewer bacteria per gram of tissue progressed to rapid uncomplicated healing. When used to determine the feasibility of reclosing incisional abscesses, the quantitative resulted in an average 14.3 day decrease in hospitalization.

Experimentally, successful closure of wounds by pedicled flaps also depends on the bacterial load in the wound at the time of closure. In heavily contaminated wounds containing $10^{6}$ bacteria per gram of tissue, neither a random nor a musculocutaneous flap was able to prevent bacterial proliferation, and all flaps dehisced. In minimally contaminated wounds containing $10^{4}$ or fewer bacteria, both the random and musculocutaneous flaps achieved wound healing and decreased the bacterial level in the wound. However, in an intermediate group containing $10^{5}$ bacteria per gram of tissue, musculocutaneous flaps lowered the bacterial count and allowed wound closure, whereas the random flaps did not control the bacterial growth and failed.

It is apparent from the preceding information that bacteria present in a wound at high levels can inhibit the normal wound healing processes and prevent wound closure by either direct approximation, skin graft, pedicled flap, or even spontaneous contraction and epithelialization.

\section{Superinfection:-}

A superinfection is a new infection that develops during antibiotic treatment for the original infection. Whenever 
antibiotics are used, they exert a selective pressure on the endogenous flora of the patient and on exogenous bacteria that colonize sites at risk. Bacteria that remain are resistant to the antibiotics being used and become the pathogens in superinfetcion.

Careful surveillance of hospitalized patients reveals superinfections in $2 \%$ to $10 \%$ of antibiotic treated patients, depending on the underlying risk factors. The best preventive action is to limit the dose and duration of antibiotic treatment to what is obviously required and to be alert to the possibility of superinfections. The use of increasingly powerful and broad spectrum antibiotics during the past 2 decades has also led to an increasing incidence of fungal superinfections.

Antibiotic Resistance:-

Antibiotic resistance is an escalating problem presenting particularly in patients in ICUs. Its implications include increased length of stay, increased costs of care and more importantly, an increased morbidity and mortality derived from infections treated unsuccessfully.

Resistance has been broadly divided into two forms (1) intrinsic resistance, in which a specific species is inherently resistant to a specific antibiotic (e.g., gram-negative bacteria to vancomycin) and (2) acquired resistance, in which a change of the genetic composition of the bacteria occurs. The acquired resistance can be the result of intrinsic changes within the native genetic material of the pathogen or can be transferred from another species.

The molecular mechanisms by which bacteria acquire resistance to antibiotics can be broadly classified into the following four categories.

1. Decreased intracellular concentration of antibiotic, either by decreased influx or increased efflux. Most antibiotics are susceptible to this mechanism (pseudomonas/Enterobacteriaceae to $\beta$-lactams)

2 Neutralization by inactivating enzymes - this is the most common mechanism of antibiotic resistance and affects all $\beta$-lactam antibiotics (e.g., $\beta$ lactamases from gram-positive and gram-negative bacteria)

3. Alteration of the target at which the antibiotic will act - It affects all antibiotics and is the main resistance mechanism for some specific bacteria (Pneumococcus to penicillin or MSRA to all $\beta$-lactam antibiotics)

4. Complete elimination of the target at which the antibiotic will act - Some specific bacteria develop the ability to create new metabolic pathways and completely eliminate a specific target.

Antibiotic resistance is usually achieved by the combination of these different mechanisms. However, the presence of one of them may confer resistance to one or more different groups of antibiotics.

The bacterial genome is divided into chromosomal DNA, which gives specific characteristics and metabolic pathways to the bacteria, and smaller, circular, and independent DNA elements (plasmids) that encode information for supplemental bacterial activities such as virulence factors and resistance mechanisms. Most resistance mechanisms are plasmid mediated, although they can interchange with chromosomal information [with the aid of transpose (mobile DNA elements)], conferring more fixed mechanisms that will be transmitted vertically. However, plasmids can also be transmitted horizontally through conjugation, transduction, and transformation processes in which different bacteria are exposed to a specific plasmid.

Risk factors for antibiotic resistance in a specific patient include use of antibiotics, prolonged hospital stays, use of broad-spectrum antibiotics, use of invasive devices (e.g., endotracheal tubes, central lines, Foley catheters) and the presence of outbreaks that may reflect ineffective infection control policies. The population at highest risk are ICU patients in which the potential absence of effective antibiotic treatments correlates with higher mortality rates.

Prevention strategies have been studied, and although it is difficult to establish a clear relation between their practice and decreased resistance, they should be part of a discipline that not only reduces the incidence of antibiotic resistance but also follows a logical practice for infection control and use of antibiotics. Some of these strategies includes guidelines for use of antibiotics (hospital formulary restriction, use of narrow spectrum antibiotics, antibiotic cycling, use of new antibiotics) assessment of infection risk and quantitative cultures, infectious disease specialists, and area specific use of antibiotics (e.g., outpatients vs. nosocomial, hospital to hospital difference). Nonantibiotic strategies include prevention of nosocomial infections (general and specific measures) and prevention of hospital transmission (hand washing, contact precautions). The battle against antibiotic resistance is definitely multidisciplinary and involves the development of new antibiotics as well as strategies in the everyday care of 
patients from all the health care personnel.

\section{Management Of Wound Infection:- \\ Risk Assessment is Useful:-}

Wound infection can be predicted to a certain extent. Because wound defenses and wound repair are vulnerable to many of the same defects, predictive of infection are usually also predictors of dehiscence or other wound failure.

The centers for Disease Control, in their study of the effect of nosocomial infection control (SENIC), developed a remarkably useful and simple predictors index ${ }^{66}$ based on a score of 0 or 1 for each of the following four patient factors: an abdominal operation, an operation that lasts 2 hours or more, an operation that is contaminated, and a patient who will have three or more diagnoses at discharge, exclusive of wound infection. The risk infection with a score of 0 is $1 \%$, with a score of 1 is $3.6 \%$, with a score of 2 is $9 \%$ with a score of 3 is $17 \%$ and with a score of 4 is $27 \%$. These percentages may seem high, but this index was constructed on $3 \%$ of the American surgical patients in 1975-1976 and 1983, and the overall results are consistent with numerous other studies. More recent risk analyses by the same group based on simpler predictors (e.g., American Society of Anesthesiologists Physical Status Classification); have yielded less sensitivity but about the same overall infection rate.

Wound oxygen tension is surgical patients generally correlate with the SENIC Score. In patients who develop surgical wound infections, however, wound po2 is almost invariably low, regardless of SENIC score. Moreover wound po2 is a significantly better predictor of infection than SENIC score. Therefore, the SENIC indices must relate to the physiologic variables that influence blood and oxygen supply. For instance, long operations often lead to increased fluid losses, hypothermia, and greater postoperative pain. The number of diagnoses correlates with poor cardiopulmonary function and more medications.

Table 1:- Preoperative checklist

Assess and optimize cardiopulmonary function. Correct hypertension.

Treat vasoconstriction: Attend to blood Volume, thermoregulatory vasoconstriction, Pain, and anxiety.

Assess recent nutrition and treat appropriately.

Treat existing infection. Among other actions, clean and treat skin infections

Assess wound risk by SENIC* score in order to decide upon the extent to which prophylactic measure should be taken.

Prescribe vitamin A or anabolic steroid therapy in patients taking prednisone. Improve or maintain blood sugar control.

* Study of the effect of nosocomial infection control, Centers for Disease Control.

\section{Preoperative preparation:-}

Cardio Vascular: Risk assessment guides preoperative preparation.

Cardiopulmonary function is obviously important. Hypertension is associated with infections and dehiscence. therefore, vasodilating antihypertensives are helpful.

We use clonidine patches (usually a no.2) applied 2 days before operation because of their ease of use. Correct blood volume deficits preoperatively if possible. Once vasoconstriction is established, blood volume deficits are difficult to correct until the vasoconstrictive stimulus (e.g., hypothermia, pain) has been corrected, as the administered volume is lost as urine.

Antibiotics: When planning antibiotics, remember that not every infection need be prevented. The significance of wound complications varies. Antibiotic usage should be judicious. Surgeons have a duty to each other to keep antibiotic use to appropriate levels in order to perturb the environment minimally. Preoperative antibiotics lose effectiveness when given too long before or after incision. Administration within 30 minutes to 1 hour of incision is ideal.

Nutrition: Assist nutrition if the patient has not eaten in the past few days or more or if the patient is expected to eat little in the days after surgery. Surgery should be delayed significantly only if malnutrition is severe In less severely malnourished patients, much can be accomplished in 2 to 3 days. In all cases, if nutritional support is begun 
preoperatively, it should be carried into the postoperative period. Any appropriate method can be used.

Diabetes: Control diabetes, including insulin, glucose, and blood volume abnormalities. Constant insulin infusions are generally superior to periodic injections in acute surgical circumstances. Hyperglycemia, among other detrimental effects, decreases vitamin $\mathrm{C}$ uptake into Cells. This can be partially overcome by supplementing vitamin $\mathrm{C}$ at 500 to $2000 \mathrm{mg} /$ day.

Steroid: Anti-inflammatory steroids hinder wound healing. For reasons that are not understood, they seem to affect the colon less than other tissues. Vitamin in oral does of 25,000 U/day, or perhaps half that intravenously, tends to overcome the inhibitory effect temporaily. It may also be used topically in chronic wounds. The effect may be mediated via TGF- $\beta$, which is decreased by steroids and returned to normal by vitamin A. Patients need the inflammatory effect of vitamin A for about 1 week after injury. Once inflammation has developed, steroids affect healing less, but their negative effect on contraction persists. Vitamin A has also been shown to correct the adverse healing effects of diabetes and radiation. Anabolic steroids are a useful alternative to vitamin A and may also elevate IGF-1 levels, probably a useful goal.

\section{Intraoperative Management:-}

New wounds are made and contaminated as operations proceed. Maintain antibiotic levels in long operations.

Anesthesia: All anesthetics tend to cause hypothermia by (1) causing vasodilatations, which redistributes heat from core to periphery in previously vasoconstricted patients, and increases heat loss, and (2) decreasing heat production, Vasoconstriction is uncommon intraoperatively, as the threshold for thermoregulatory vasoconstriction is decreased, but is often severe in the Immediate postoperative period, when anesthesia is discontinued and the thermoregulatory threshold returns to normal in the face of a core temperature of 34 to $35.5 \mathrm{C}$ The onset of pain with emergence from anesthesia often adds to this vasoconstriction. Maintenance of normothermia intraoperatively has recently been shown to decrease the wound infection rate by two thirds in patients undergoing colon surgery. Rapid rewarming of hypothermic patients in the post anesthesia care unit appears also to be effective. Maintenance of a high room temperature and forced air warming before, during, and after the operation are far superior to other methods of warming such as circulating water blankets placed under the patient and humidification of the breathing circuit.

\section{Intraoperative Management:}

Appropriate prophylactic antibiotics should be given at the start of any procedure in which infection is highly probable and / or has potentially disastrous consequences. Keep antibiotic levels high during long operations.

Keep patient warm.

Observe gentle surgical technique with minimal use of ties and cautery. Keep wounds moist. Irrigate with antibiotics in contaminated cases.

Elevate $\mathrm{PaO}_{2}$.

Delay closure for heavily contaminated wounds. Use appropriate sutures (and skin tapes).

Use appropriate dressings.

Fluid replacement: Replace fluid losses aggressively: 10 to $15 \mathrm{mg} / \mathrm{kg} /$ hour plus three to four times the blood loss (crystalloid) during major abdominal surgery. This takes into account third-space losses as well as the preoperative fluid deficit, which is especially great after a bowel preparation. Dark venous blood in the incision usuallyindicates vasoconstriction, not poor ventilation.

Surgical technique: Use gentle and clean surgical technique. Plan incision with regard to blood supply, particularly when operating near or in old incisions. Release mechanical retractors from time to time to allow perfusion. Judicious antibiotic irrigation of contaminated areas is effective. Because dried wounds lose perfusion, keep wounds moist, especially during long operations. Not all wounds can be anatomically closed. Edema, obesity, the possibility of unacceptable respiratory compromise, and need to debride abdominal or chest wall tissues can interfere with closure. A variety of polymeric -fabricsll is available to interpose between the wound edges. Their use 
is preferable to evisceration on the one hand or respiratory.

Compromise on the other. If the problem is temporary, the implant can be removed in a few days. Polypropylene mesh was designed to allow granulation tissue to penetrate the interstices and can be left permanently. When stiff mesh materials are left longer, fistulas sometimes develop. Unfortunately, soft Teflon meshes, although useful in primary healing, are poorly incorporated into granulation tissue and eventually require removal when involved in secondary healing.

Suture material: Use modern sutures. They are very good. Although silk is acceptable for some uses and surgeons traditionally prefer its handling characteristics, multifilament nylon handles well and is less inflammatory and more permanent. If skin sutures are necessary, use monofilament absorbable material, preferably a subcutaneous closure. Modern monofilament absorbable suture materials are preferred for deep closures as well. A spectrum of absorption times is available. The time to half loss of suture strength is usually the index of absorbability. Mass is lost more slowly. Polylactide sutures are most suitable for subcutaneous closures and are preferable to catgut in essentially all circumstances. Use the finest gauge compatible with the strength needed. Most surgeons use sutures that are a size larger than necessary. The tendency to suture sinus formation is proportional to the size of the suture as well as the material. Deep tissues, abdominal and chest wall, deep fascia, and synovium can be closed with running or interrupted sutures as indicated by other considerations. However, closure should never be excessively tight and should allow for the inevitable swelling. In high-risk abdominal closures, large monofilament sutures should be placed at least $2 \mathrm{~cm}$ back from the wound edge and about the same distance apart. Suction drains are usually more successful than subcutaneous sutures for closing potential dead spaces. Irrigate out such small particles as fat detritus, which must be phagocytosed and removed by leukocytes and thus slows the rate of bacterial clearance.

Skin tapes with or without buried subcuticular closure are still the most infection free closure! Staples are slick and quick but difficult to place without compressing local microvasculature and entering the wound space. If you cannot be truly expert in their use, do not use them. To tell the difference, examine staple-closed wounds at about 7 days. Erythema and scarring at the entrance points indicate that the staples were placed too tightly.

\section{Wound dressing:-}

Dressing technique is not critical on primarily closed operative wounds because resistance to external contamination builds rapidly, within a few hours. Skin tapes covered by a simple gauze dressing usually suffice. Open, incised wounds should be dressed with nonadherent material covered by an occlusive moisture- retaining material that can be changed daily if necessary. However, if delayed primary closure is intended, the dressing should not be disturbed until the fourth or fifth day or until troubles develop. Healing is most rapid and pain is least with oxygen-permeable, plastic adherent sheets over skin graft donor sites and extensive abrasions.

Delayed primary closure should be considered when wound infection seems highly probable. Wisely used, delayed closure can prevent infection and unnecessary scarring. Closure can almost always be accomplished on the ward or in the office using skin tapes and no anesthesia. Consider leaving contaminated subcutaneous tissue open for delayed primary closure on the fourth or fifth postoperative day not beforeorafter.

\section{Postoperative management:-}

Wounds are most vulnerable in the early hours. Although antibiotics lose their effectiveness after the first hours, natural wound immunity lasts longer. Even a short period of vasoconstriction during the first day is sufficient to reduce oxygen supply. Correction of vasoconstriction in the first 24 to 48 hours after surgery has significant beneficial effects.

Third space losses continue for about 24 hours and then abate. Using tissue oxygen probes, we find that the routine postoperative fluid order of 100 to $150 \mathrm{ml} / \mathrm{hr}$ is inadequate to maintain wound perfusion for the first 12 to 24 hours after most abdominal and chest operations. It is useful to make routine assessment of the degree of vasoconstriction, an indirect indicator of wound $\mathrm{p} 02$.

Unfortunately, urine output is a poor, often misleading guide to peripheral perfusion. Markedly low output may indicate decreased renal perfusion, but normal or even high urine output has little correlation with wound and tissue Po2. Many factors commonly present in the postoperative period, including hyperglycemia, dye administration, thermoregulatory vasoconstriction, adrenal insufficiency and various, may cause inappropriate diuresis in the face of mild hypovolumia. 


\section{Post Operative Management}

Keep patient warm

Provide analgesia to keep patient comfortable, if not pain free. Patient report and the ability to move freely are the best signs of adequate pain relief.

Administer one more dose of antibiotic unless an infection is present or contamination continues. Keep up with third-space losses. Remember that fever increases fluid losses. Assess perfusion and react to abnormalities.

Avoid diuresis until pain is gone and patient is warm. Assess losses (including thermal losses) if wound is open. Assess need for parenteral/enteral nutrition and respond. Continue to control hypertension and hyperglycemia.

Physical examination of the patient is a better guide to dehydration and vasoconstriction. Assess vasoconstriction by a capillary return time more than 1.5 seconds at the forehead and more than 5 seconds over the patella. Dehydration is best assessed by eye turgor (use your own as a control if you have not missed lunch and do not have glaucoma), and patients can usually distinguish thirst from dry mouth. Skin should be warm and dry. Vasoconstriction due to any cause increases the urinary output. A high urine output when the patient is cold turns to a low one when he or she is warmed. If the patient has good peripheral perfusion on physical examination, a moderately low (but equate urine output is usually best ignored because aggressively ministering fluids in this circumstance is one of the most common things for pulmonary edema.

When excessive tissue fluids have accumulated, diuresis should be undertaken gently so that transcapillary refill can maintain blood volume. This applies to patients who need renal dialysis as well. Fluid losses from the vascular system are not necessarily replaced from the tissues as rapidly as they are sustained. The average dialysis patient vasoconstricts sufficiently to lower tissue Po2 by $30 \%$ or more during dialysis and needs about 24 hours to return vasomotor tone and wound tissue Po2 to normal.

Local perfusion is not ensured until patients have a normal blood volume, are warm and pain free, and are receiving no vasoconstrictive drugs that is, until the sympathetic nervous system is inactivated. Warning should continue until patients are thoroughly awake and live and can maintain their own thermal balance. After major operations warming may be useful for many hours or even days. The goal is skin warmth, and wound vasoconstriction due to cold surroundings often co-exists with core hyperthermia. Moderate hyperthermia is not itself a problem. When extensive wounds are left open, warmth should be continued, and heat losses due to evaporation should be prevented avoid vasoconstriction and to minimize caloric losses.

Vasoconstrictive drugs should be avoided, the most common and most avoidable are smoking and beta blockers. Both are known to reduce wound and tissue Po2. But in a limited experience we have found that the so-called renal dose ( 3 to $5 \mathrm{ug} / \mathrm{kg} / \mathrm{min}$ ) of dopamine has little or no effect on wound and tissue p02.

Maintenance of tissue p02 requires attention to pulmonary function postoperatively. Pain control appears important because it favorably influences both pulmonary function and vascular tone. This is particularly true in patients at high risk for pulmonary complications postoperatively, such as morbidly obese patients and those with pulmonary disease. Epidural analgesia may be the route of choice in these patients. It has several advantages over parenterally administered opioids in that it generally achieves lower pain scores with less sedation. Nonetheless, opioid-induced pruritus is more common with epidural administration and, in some patients, may be severe enough to counteract the benefits of pain control.

Patient-controlled analgesia (PCA) is also quite effective at achieving low pain scores. It also has the benefit of giving control to the patient, leading to patient satisfaction as high as with epidural analgesia in many cases 85 . Nurse-administered, 
as-needed dosing of intravenous or intramuscular opioids should be avoided, as inadequate pain control is common (often exceeding 5\%) with this approach ${ }^{86}$. The key to pain control is recognition of the need for analgesia and attention the patient's complaints of pain. Opioid requirements vary enormously and are not always predictable, but even tolerant patients (intravenous drug abusers and those with cancer pain) can be given adequate pain relief with sufficient attention.

\section{Treatment of wound infection:-}

Re-establishment of the bacterial balance and wound closure:-The various types of wound infections discussed are all considered -surgicalll infections. Wound infections require surgical principles such as drainage of an abscess, debridement of necrotic tissue, and well-time wound closure. All surgical therapy in the infected wound must be directed toward establishing the balance and rendering the local environment and bacterial flora suitable for closure. Therefore, in addition to drainage, surgical debridement must remove residual necrotic tissue, hematoma, and foreign bodies, including sutures. The specific wound infections require somewhat different techniques to reestablish equilibrium.

\section{Treatment of the infected incision:-}

Compared with the other type of wound infection to be discussed, the operative incision is one that responds best to preventive measure. $\|$ Clean, $\|$-clean-contaminated, $\|$ and even -contaminated\| wounds are usually in bacterial balance. 28 Tissues from -contaminated $\|$ wounds rarely yield bacterial counts in excess of $10^{5}$ bacteria per gram of tissue. Only in "dirty" wounds should one routinely expect large numbers of bacteria.

If the bacterial inoculum is not excessive, as would be expected in the majority of incisions, infection can be prevented by maintaining the host defenses at peak efficiency. The effect of the interaction between the bacteria and the host, although under systemic influence, is ultimately determined by the local factors in the wound. Among these are necrotic tissue, decreased local wound perfusion, foreign body, hematoma and dead space. Surgeons can do little to change systemic host defense factors such as age, obesity, malnutrition, chronic steroid administration, and specific immune defects. However, the surgeon plays a significant role in eliminating the local deterrents to effective host defense in the wound. If local wound factors are not controlled, they upset the equilibrium. Circumstances are then produced in which a normal subinfectious inoculum of bacteria may multiply to levels sufficient to produce infection.

The most important factor introduced in the past half century to alter the balance between host resistance and bacteria has been the use of antibacterial agents. The administration of these agents at the proper time, by the proper route, and in the proper dosage to be therapeutically effective should theoretically be able to prevent or treat infection from organisms susceptible to the agent administrated. However, the proliferating use of antibiotics has failed to eliminate infection. In fact, it has led to many more abuses than effective uses. One cannot and should not desire to create a

-germ-freell patient. Systemic antibiotics have practical and potential value only if a therapeutic blood level or, more importantly, tissue level is achieved within the first 4 hours after wounding. Burket has shown that bacterial lodgment is not influenced by wounding. Burket has shown that bacterial lodgment is not influenced after that time. When antibiotics are begun after the time required for bacterial lodgment, infection rates are higher than when no antibiotics are used. A review of the principles of prophylactic antibiotic usage is beyond the scope of this paper, so the reader is referred to the excellent discussion of the subject by Meakins.

When prevention is not successful, an incisional wound infection occurs. A grossly infected wound is one in which purulent material is obtained from the wound or one with surrounding cellulitis and inflammation beyond that appropriate for normal wound healing. The treatment of these two clinical presentations is different. For the wound with spreading cellulitis and no loculation of pus or drainage, systemic antibiotics can be useful. If the wound is not opened, extreme vigilance is required so as not to miss an inapparent loculation. If the wound quickly responds to the systemic antibiotics, the original closure may be maintained.

If the wound drains purulent material or a loculation is suspected, the wound should be opened. It is important not to get too concerned about the purulent material within the wound. It should be irrigated from the wound, and material for a tissue 
biopsy should be obtained from the wall of the abscess. In reported studies, the wound biopsy revealed the causative organism in $87 \%$ of cases. However, cultures of the purulent exudates often reveal multiple organisms and not those responsible for tissue invasion. A Gram stain of any purulent material may be of use to identify clostridia when they are present. Culture of the purulent material is not as useful as culture of tissue from the wound wall. The fact that tissue biopsies usually yield a single bacterial species is very helpful if systemic antibiotics are chosen in the treatment of the abscess.

Once the wound has been prepared and a tissue biopsy has identified the causative organisms, the goal is to reestablish the bacterial balance in the wound. The techniques for this are the same as those for a chronically contaminated wound, to be discussed later. Topical antimicrobials and temporary biologic dressings are useful.

When the wound is in bacterial balance $\left(10^{5}\right.$ bacterial per gram of tissue or fewer), delayed closure can be performed. Howe has stated that once a contaminated wound has been converted to a -clean\| wound, it can be treated as any other wound and surgically closed. In a series of delayed closures based on bacteria counts reported by the author, incisional abscesses were reclosed with a $96 \%$ success rate. In localized incisional abscesses that have been drained and are being treated as chronically; contaminated wound, systemic antibiotic are not used. They are reserved only for those wounds in which infection appears to be spreading through the subcutaneous tissue even after drainage of the wound and debridement of the infected soft tissue.

\section{Treatment of the Acutely Contaminated Wound:-}

As previously discussed, all traumatic wounds should be considered contaminated. However, not all are infected and present with greater than $10^{5}$ bacteria per gram of tissue. The history of wounding, the wounding agent, wound location, and timing can all help suggest the level of bacteria in a wound. If the suspicion is high or if the patient presents more than 5 hours after injury, a tissue biopsy and rapid slide evaluation are warranted. Management of the acutely contaminated wound is undertaken with the goal or re-establishing the bacterial balance, if indeed it is weighted in favor of the bacteria, and managing the wound as if it were a clean one. The mainstay of management is sharp debridement, which indeed is the sine qua non of contaminated wound management. All debris and nonvitalized tissue should beexcised. The edges of the wound should be freshened and, when possible, made perpendicular to facilitate closure.

Irrigation is an important adjunct to sharp debridement. Low-pressure wound irrigation removes little but surface contamination, even with voluminous amounts of solutions. Therefore, irrigation should be high pressure and intermittent. In an experimental animal system, the pulsating jet lavage was shown to remove significantly more bacteria and result in fewer wound infections than the more conventional low-pressure irrigation. If the wound is small and has minimal contamination, a modification of the pulsating jet lavage can be constructed using a syringe with a 19-gauge needle. Again, irrigation is most efficiently done with an intermittent-pressure technique so as to allow the normal elasticity of soft tissue to assist in removal of bacteria and foreign bodies.

Systemic antibiotics are of little use in treatment of the acutely contaminated wound. They have practical and potential value only if a tissue level can be achieved within the first 4 hours after wounding, which is almost impossible in the first 4 hours after 4 hours after wounding, which is almost impossible in the acutely contaminated traumatic wound. When antibiotic are begun after the time required for bacterial lodgement, infection rates may be higher than when no antibiotics are used. Surgical debridement and freshening of the wound may render this restriction less rigid and make antibiotics more effective. Also, recent data about the role of inflammatory mediators suggest that once vasoconstriction mediators are present, wound penetration of antibiotics may be less efficient. Therefore, debridement and adjunctive irrigation remain the mainstays of treatment of the acutely contaminated wound.

Once bacterial balance has been re-established, wound closure can proceed as for a clean wound. If circumstances suggest the need for a tissue biopsy, either a rapid slide evaluation or full bacterial quantitative and qualitative analyses can be performed. When $10^{5}$ of fewer bacteria per gram of tissue are present, wound closure can proceed.

However, if greater than $10^{5}$ bacteria per gram of tissue are present, the wound should be temporarily left open for delayed closure. The principles learned in military surgery are equally operative in potentially contaminated civilian wounds; 
that is, when in doubt it is safer to leave a wound open. It has been repeatedly shown that delayed closure can be performed as easily as those for acute clean wounds if the level of bacteria has been sufficiently reduced to reestablish the bacterial balance.

\section{Treatment of the Chronically Contaminated Wound:-}

As defined earlier, when granulation tissue is present and a wound is not proceeding through a timely and orderly healing trajectory, it is a chronic wound. These wounds are frequently not in bacterial balance. Not only is the inoculum great but often the bacterial host defenses are impaired, as in the diabetic foot ulcer.

It has been shown in blinded studies that it is clinically impossible to predict bacterial balance in a chronic granulating wound. In some wound, creeping epithelium form the wound edges has been a useful sign in predicting when a wound can be successfully closed. However, statistically, the best method has been the use of quantitative bacterialogy on a tissue biopsy specimen When wound have greater than $10^{5}$ bacteria per gram of tissue or betahemolytic streptococci are present, they cannot be successfully closed. Therefore, the goal of management in these chronically contaminated wounds with granulation tissue is to decrease the bacterial count in the granulation tissue to $10^{5}$ or fewer bacteria per gram of tissue. Management of these wounds consists of various techniques to decrease the bacterial count. Reduction of the bacterial flora is best accomplished by meticulous attention to surgical detail. Frequent debridement and surgical cleansing are critical. Enzymatic debridement may be of some value, but it tends to allow simultaneous rapid bacterial proliferation. This is a potential danger, particularly when large areas are involved, such as in thermal burns. Systemic antibiotic have been demonstrated not to reach adequate tissue level in chronic granulation tissue and to have no effect on the bacterial levels in chronic granulating wounds. Conversely, water-based topical antibacterial creams do penetrate the depths of such wounds and have a direct effect on bacterial growth.

Because true bacterial control is achieved only by wound closure, the use of temporary biologic dressings for cleansing and temporary closure has been shown to be of value. In a randomized study of 100 delayed wound closures, the authors compared several methods to decrease the bacteria to below the critical level Temporary biologic dressings proved to be the most effective. The biologic dressings probably adhered to the wound surface and affected a =biologic closure" that allowed the inflammatory tissue to function at peak efficiency and phagocytosis to proceed effectively. However, true control of infection in granulating wound is closure of the wound with autologous tissue.

Techniques of closure in chronically contaminated wounds vary widely, depending on the circumstances. However, once the wound is in bacterial balance, with $10^{5}$ or fewer bacteria per gram of tissue and no beta-hemolytic streptococci in the wound, closure by direct approximation, skin graft, or flap can be predictably successful. Successful closure by one of these methods eradicates the remaining bacteria in the wound.

\section{Antibiotics:-}

This review is intended to summarize key elements in the field of wound infections; a prolonged reiteration of the literature on antibiotic prophylaxis in surgery is therefore not necessary. An excellent set of recent guidelines has been published by Page and other members of the Surgical Infection Society; the following is a brief summary of those recommendations.

\section{Clean wounds:-}

In general, clean wounds do not require antimicrobial prophylaxis. The most common exceptions are procedures in which infection would be disastrous, including prosthesis placement, central nervous system operations, and cardiac procedures requiring cardiopulmonary bypass. Despite recent assertions to the contrary, routine prophylaxis for breast surgery or herniorrhaphy is still not recommended for otherwise healthy, low risk patients. a first generation cephalosporin, such as cefazolin, or vancomycin if the patient is significantly penicillin allergic, is most commonly used.

Clean contaminated wounds:-

Clean contaminated wounds benefit from antimicrobial prophylaxis. Head and neck, noncardiac thoracic, biliary, genitourinary, and gastroduodenal procedures in patients with acid suppression, bleeding ulcers, or gastric cancer 
should receive cefazolin or an equivalent regimen unless preoperative cultures identify resistant organisms (e.g., from an infected biliary tree). Colorectal operations should receive mechanical bowel preparation and oral antibiotic, usually $1 \mathrm{~g}$ each of neomycin and erythromycin base at 1,2 and $11 \mathrm{PM}$ the day before surgery. Most surgeons add cefoxitin or an equivalent regimen active against aerobes and anaerobes as parenteral prophylaxis, although the added benefit of this is not completely proven. Appendectomies should be managed with cefoxitin prophylaxis or its equivalent.

\section{Dirty wounds:-}

Cases known or expected to be dirty, such as abdominal trauma, should receive preoperative antibiotics, which are commonly continued in the postoperative period as active treatment. It is now clear that both the facultative gram negative aerobic and anaerobic components of this contamination need to be covered. Cefoxitin or an equivalent combination, such as gentamycin and clindamycin, is considered acceptable.

Other recommendations include giving prophylactic antibiotics no sooner than on induction of anesthesia, timely redosing of antibiotics intraoperatively, limiting prophylaxis to 24 hours, and avoidance of excessively broadspectrum antibiotics for prophylaxis.

\section{Role of hyperbaric oxygen:-}

Several mechanisms are postulated by which HBO may assist in control of both the infections process and wound healing.

1. HBO increases the oxygen tension in the tissue bordering the infection, which is made ischemic by the inflammatory response and various bacterial toxins.

2. Leukocytes are activated and oxygen can be used as a substrate to produce an

3. increased concentration of oxygen free radicals necessary to kill the phagocytosed microbes.

4. The increased oxygen tension may have a direct antimicrobial effect by decreasing the multiplication of anaerobes.

5. The production of endotoxin released by reflex vasodilatation caused by the hypoxic inflammatory state. This may result in a decrease in the tissue edema, which could enhance the host's ability to fight the infection.

6. Capillary angiogenesis is enhanced, as is fibroblast proliferation, which may lead to more rapid granulation tissue and wound healing.

\section{Methodology:-}

The Clinical Study Of Postoperative Wound Infection was conducted at Yenepoya Medical College \& Hospital during the period of October 2013 to October 2015.

\section{Inclusion criteria:-}

Only those cases which will be operated in Yenepoya Medical College \& Hospital will be taken into consideration. Age limits: 15- 80years

\section{Exclusion criteria:-}

Wound site previously infected will be excluded

\section{Materials and Methods:-}

An elaborate study of these cases with regard to date of admission, history, clinical features of wound infection, special investigation, type of surgery, preoperative preparation and postoperative management is done till patient is discharged from hospital.

In history, presenting complaints, duration, associated diseases, personal history including diet, smoking, alcoholism were note

Preoperative findings which include preoperative bath, skin preparation, type and time of preparation $(<24$ or $>24$ hours) preparation of bowel, preoperative antibiotics, steroid medication were noted. Operative findings which include, wound irrigative drain and its type (open or closed) noted.

Postoperative findings which include, day of diagnosis of infection, day of $1^{\text {st }}$ dressing and frequency of change of 
dressing, local application of antibiotics and postoperative antibiotics.

Findings on the day of diagnosis of wound infection were noted which included fever, erythema, discharge, type of discharge.

Wound infection was diagnosed on the basis of definitions given in Oxford textbook of Surgery, $2^{\text {nd }}$ edition, swab for culture and sensitivity is collected and sent to laboratory with appropriate specimen (discharge).

\section{Procedure in laboratory:-}

As soon as swabs were received in laboratory swabs were immediately put in glucose broth, the content were inoculated to blood agar plate and incubated at 37 for 18 to 24 hours. Colonies are studied morphologically.

Further colonies were inoculated in peptic water for gram negative bacilli and glucose broth for gram positive cocci. Both were incubated for 4 hours.

Gram negative organisms are identified by different media for which tubes were used

1. Triple sugar iron agar tube

2. Keoser citrate tube

3. MR tube

4. Urea tube

The reports for all 210 cases is made into a chart. Each organism cultured is noted and the number of times it is isolated in written correspondingly. This gives the commonest microorganisms in our hospital setting.

Most sensitive and resistant antibiotics:

After the culture of micro-organism, sensitivity test is done. Sensitivity test is done in our laboratory by using

1. Blood agar plate,

2. Mueller's hinston plate

These plates are incubated over night and then the sensitivity is confirmed.

These reports were charted and separate graph was prepared showing the sensitivity and resistance of individual antibiotic. One more graph was prepared by giving one point for each time antibiotic is sensitive and one point for each time antibiotic is resistant. This graph shows the most effective antibiotic which is having highest positive value.

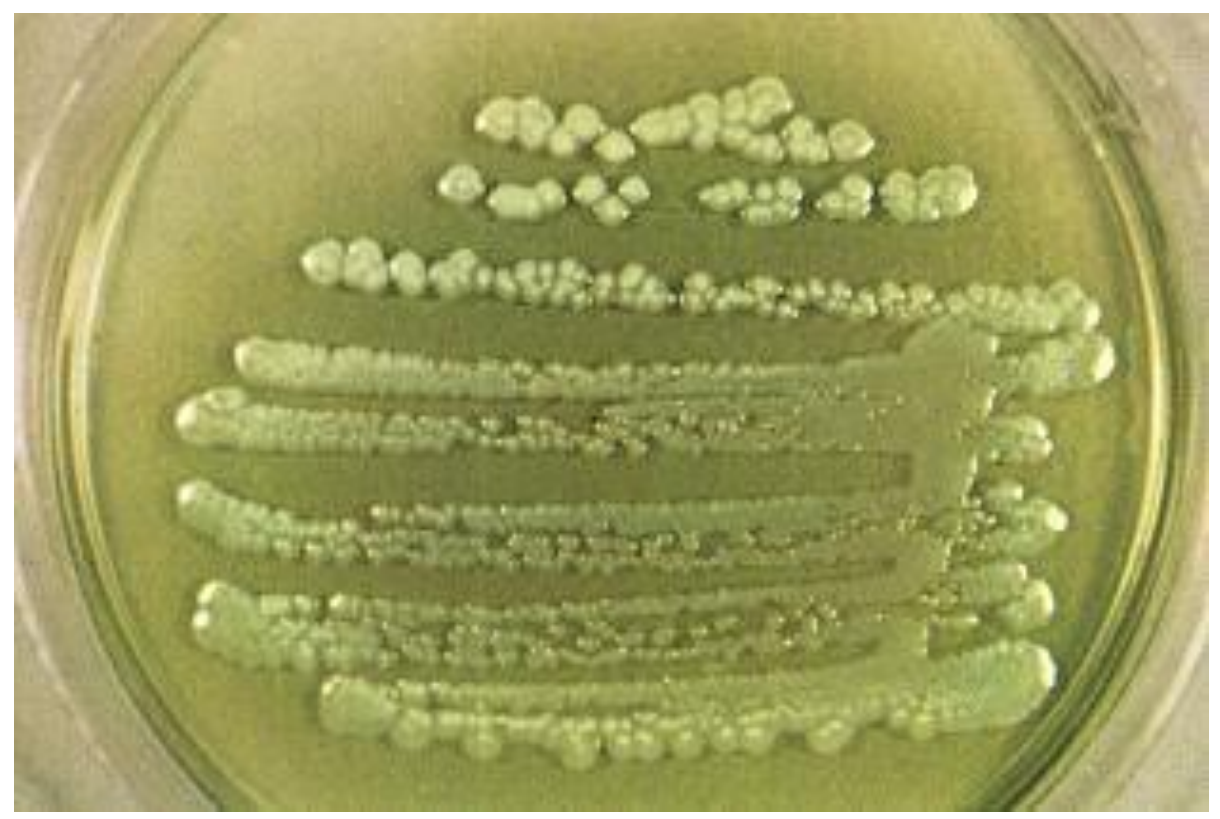




\section{Cluture Plate}

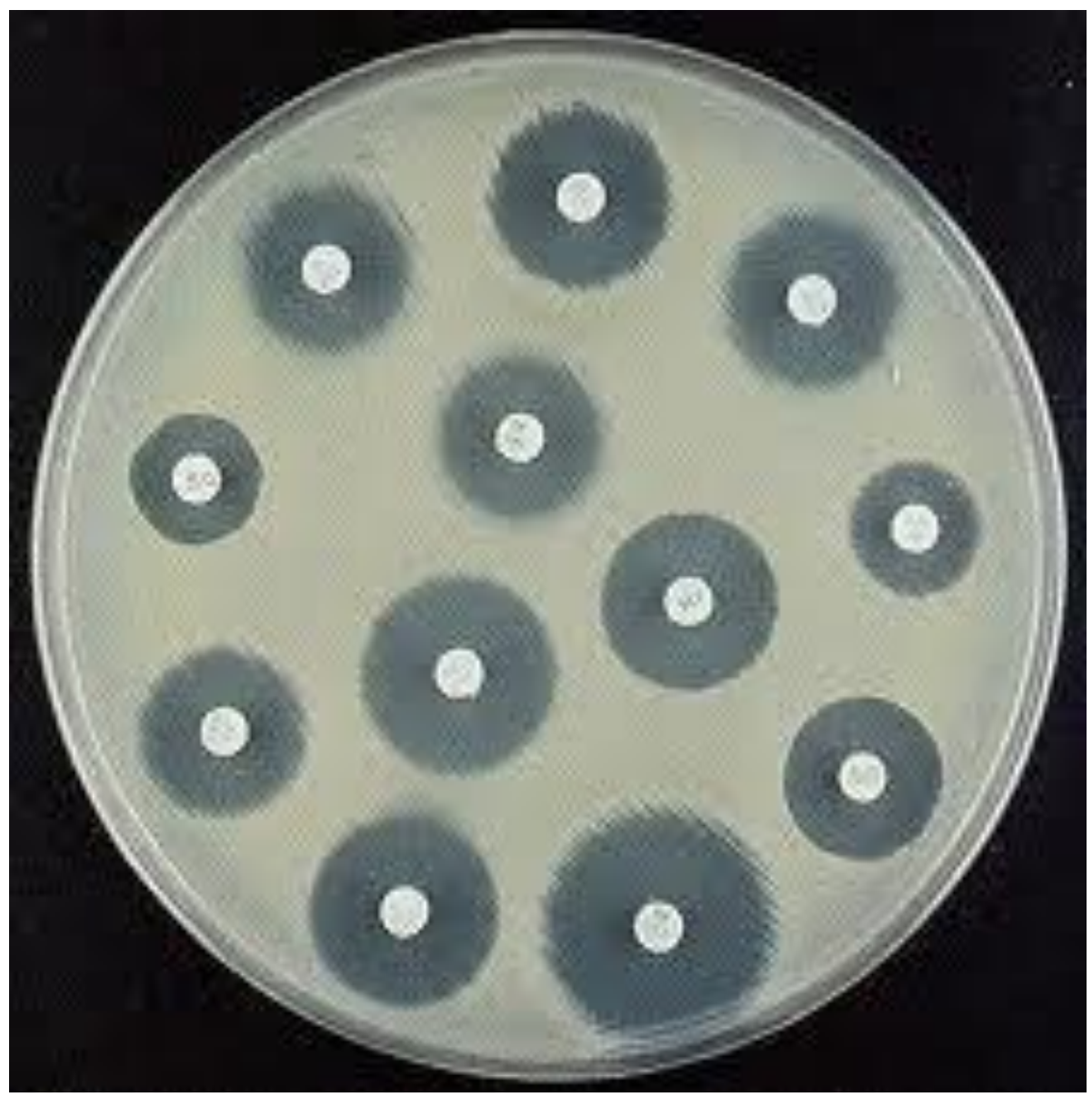

Antibiotic Sensitivity Test

Observation And Results:-

Age wise distribution of study subjects:-

In this study majority of patients belonged to the age group between $41-50$ years. Youngest patient was 15 years old and oldest was 80 years. The mean age of the patient affected was 44 years.

\begin{tabular}{|l|l|l|}
\hline & AGE & Percent \\
\hline$<20$ & 21 & $10 \%$ \\
\hline $\mathbf{2 1 - 3 0}$ & 33 & $15.7 \%$ \\
\hline $\mathbf{3 1 - 4 0}$ & 39 & $18.6 \%$ \\
\hline $\mathbf{4 1 - 5 0}$ & 48 & $22.9 \%$ \\
\hline $\mathbf{5 1 - 6 0}$ & 27 & $12.9 \%$ \\
\hline $\mathbf{6 1 - 7 0}$ & 21 & $10 \%$ \\
\hline $\mathbf{7 1 - 8 0}$ & 21 & $10 \%$ \\
\hline Total & 210 & $100 \%$ \\
\hline
\end{tabular}




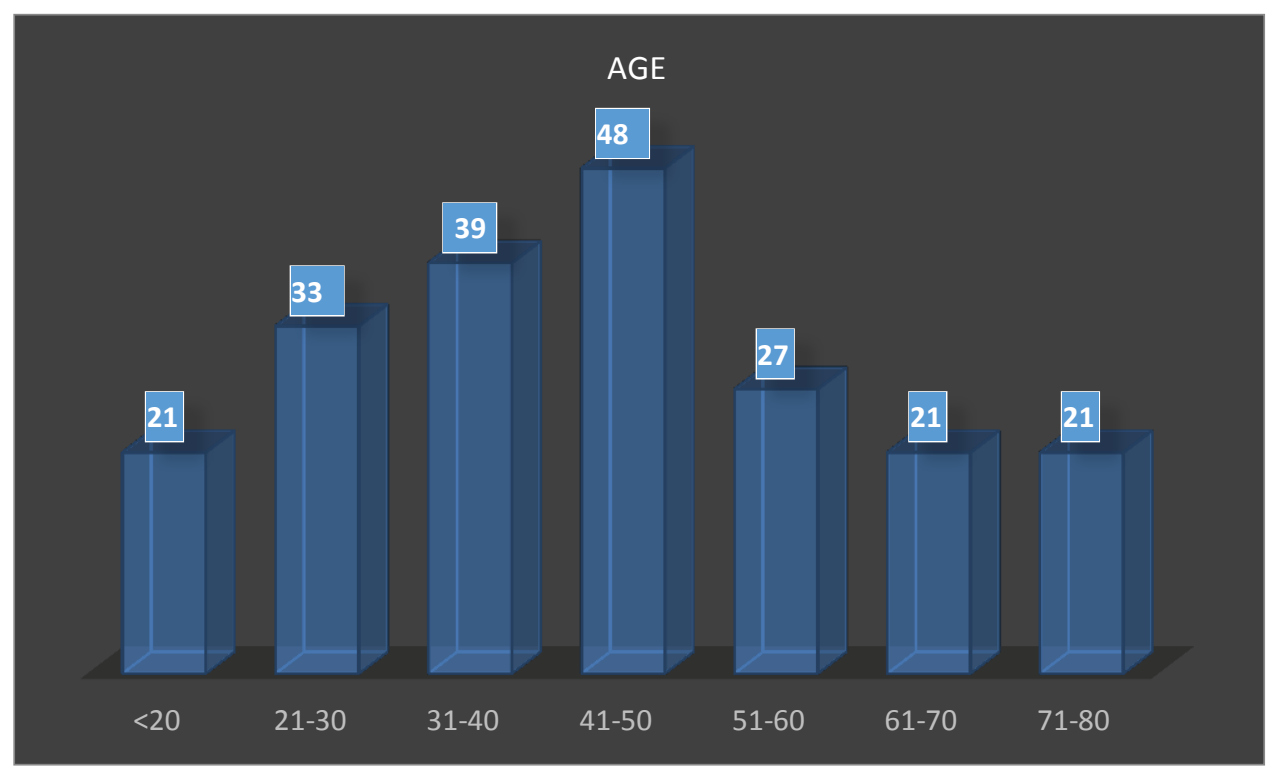

\section{Sex wise distribution:}

Out of 210 cases, 153 cases were male and 57 female cases. The percentage in present series is $72.9 \%$ for males and $27.1 \%$ for females.

\begin{tabular}{|l|l|l|}
\hline & SEX & Percent \\
\hline F & 57 & $\mathbf{2 7 . 1 \%}$ \\
\hline Total & $\mathbf{1 5 3}$ & $\mathbf{7 2 . 9 \%}$ \\
\hline
\end{tabular}

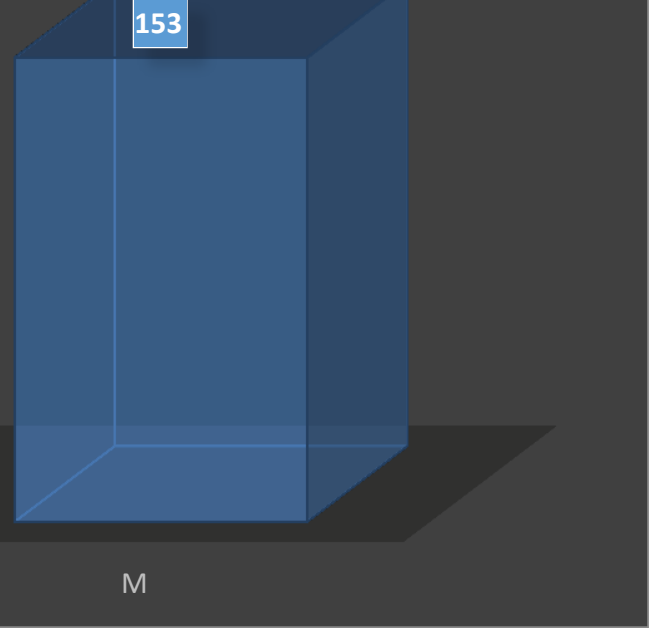




\section{Diagnosis wise distribution:}

In present series, the most common diagnosis of affected cases was _ACUTE APPENDICITIS‘. The total number of cases are 14 , giving percentage of $20 \%$.

\begin{tabular}{|l|l|l|}
\hline & DIAGNOSIS & Percent \\
\hline ACUTE APPENDICITIS & 42 & 20 \\
\hline APPENDICULAR PERFORATION & 27 & 12.9 \\
\hline CA BREAST & 12 & 5.7 \\
\hline CA OESOPHAGUS & 3 & 1.4 \\
\hline CA PANCREAS & 3 & 1.4 \\
\hline CA RECTUM & 3 & 1.4 \\
\hline CA STOMACH & 9 & 4.3 \\
\hline DIAPHRAGMATIC RUPTURE & 3 & 1.4 \\
\hline DUP & 24 & 11.4 \\
\hline HYDROCELE & 15 & 7.1 \\
\hline INTESTINAL OBSTRUCTION & 33 & 15.7 \\
\hline INTESTINAL PERFORATION & 18 & 8.6 \\
\hline LT INGUINAL HERNIA & 6 & 2.9 \\
\hline RT INGUINAL HERNIA & 3 & 1.4 \\
\hline UMBELICAL HERNIA & 6 & 2.9 \\
\hline VARICOSE VEIN & 3 & 1.4 \\
\hline TOtal & 210 & 100 \\
\hline
\end{tabular}

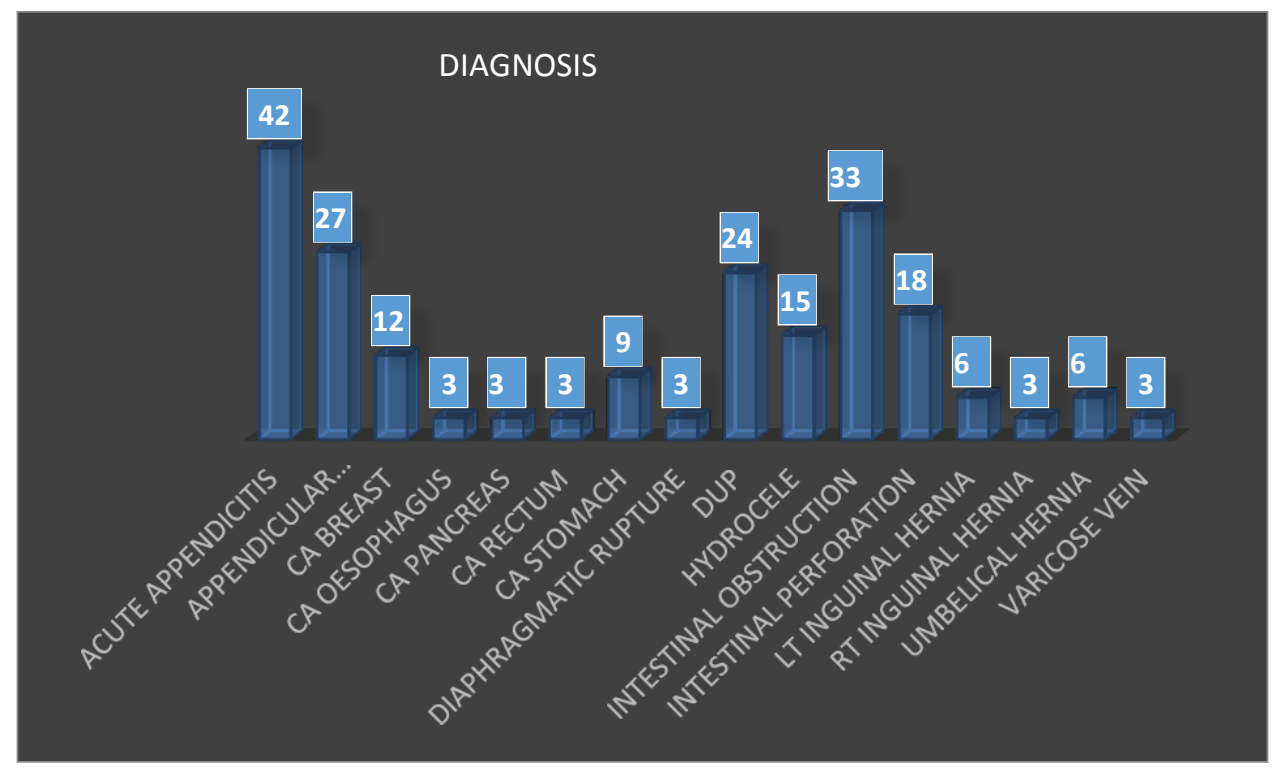




\section{Signs and symptoms:-}

The most common presentation in present series is discharge. Total 153 cases presented with discharge through the wound.

\begin{tabular}{|l|l|l|l|}
\hline & & Count & Column N \% \\
\hline FEVER & - & 99 & $47.10 \%$ \\
\hline & + & 111 & $52.90 \%$ \\
\hline ERYTHEMA & - & 141 & $67.10 \%$ \\
\hline DISCHARGE & + & 69 & $32.90 \%$ \\
\hline & - & 57 & $27.10 \%$ \\
\hline & + & 153 & $72.90 \%$ \\
\hline
\end{tabular}

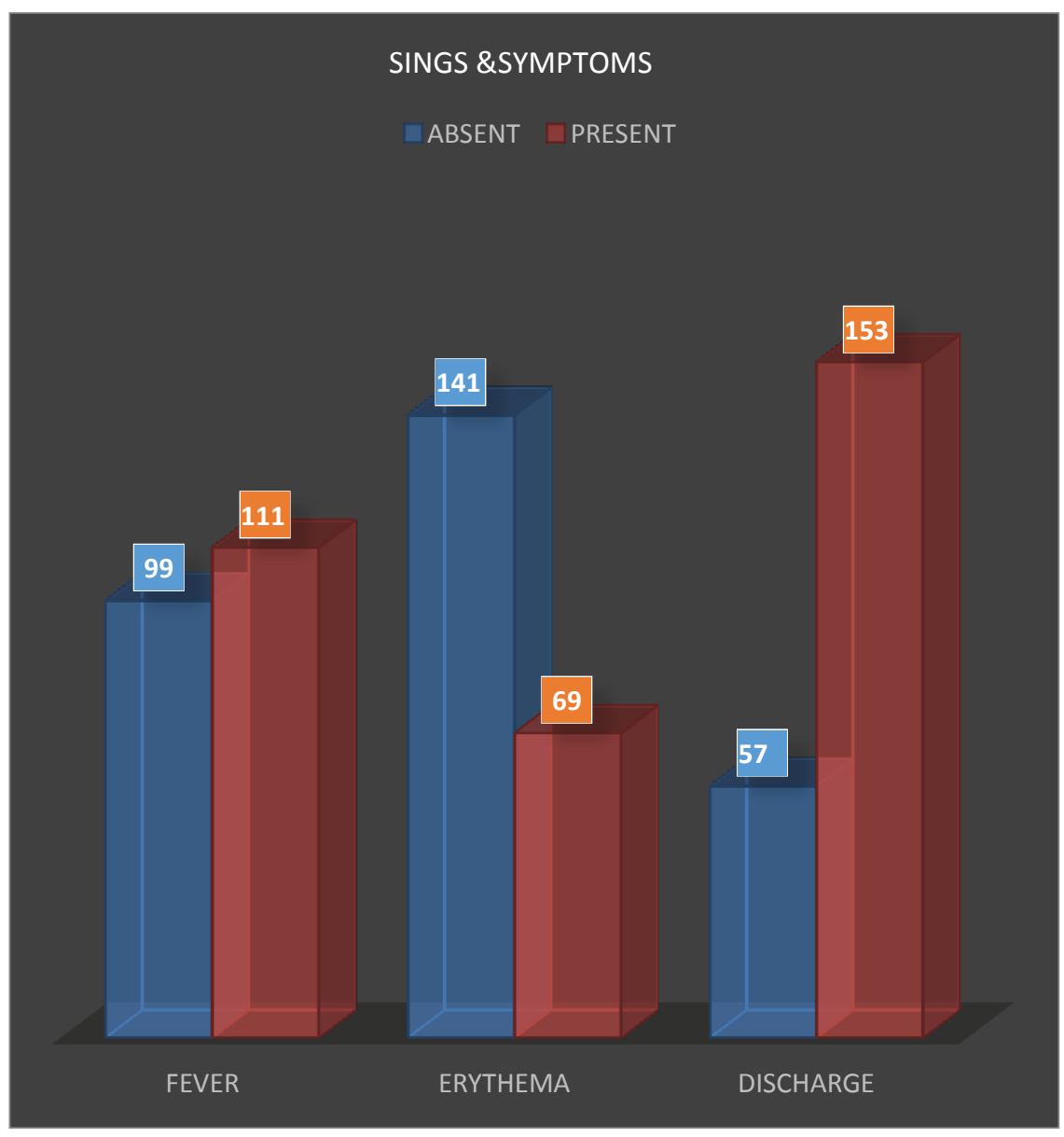

\section{Type Of Discharge:-}

The most common type of discharge was _purulent' type with percentage of $31.40 \%$ In 66 case the least common type of discharge was Serosanguinous . Only patient presented with Serosanguinous discharge with percentage of $20 \%$ In 42 case.

\begin{tabular}{|l|l|l|l|}
\hline DISCHARGE TYPE & NIL & $\mathbf{6 2}$ & $\mathbf{2 5 . 7 0 \%}$ \\
\hline & Purulent & 66 & $31.40 \%$ \\
\hline & Seropurulent & 48 & $22.90 \%$ \\
\hline & Serosanguinous & 42 & $20.00 \%$ \\
\hline
\end{tabular}




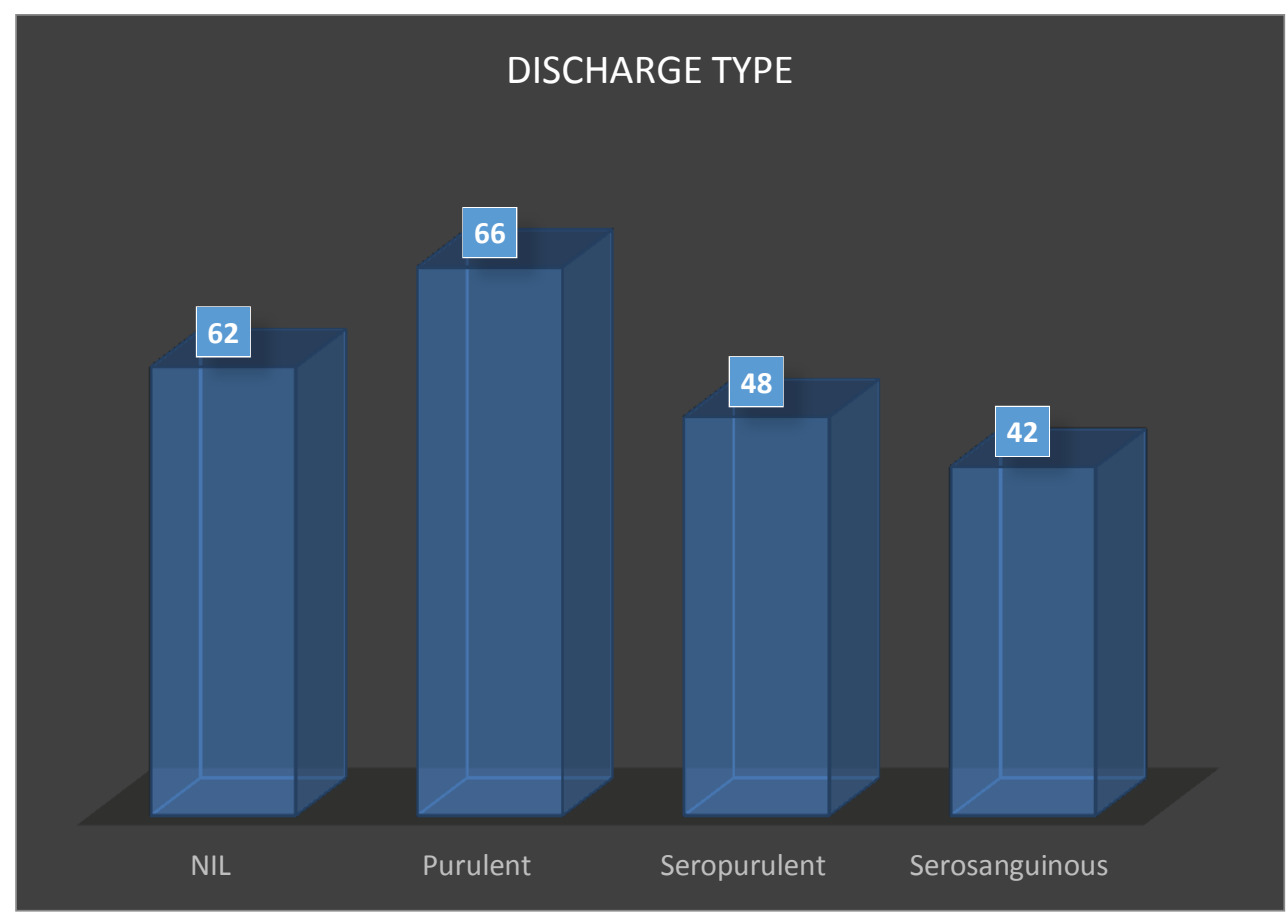

Frequency of change of dressing:-

In present series the dressing was changed daily. Out of 210 cases, in 159 cases the dressing was changed on daily.

Frequency of change of dressing

\begin{tabular}{|l|l|l|}
\hline Frequency of change of dressing & No of Cases & Percentage \\
\hline Alternate day & 51 & $24.3 \%$ \\
\hline Daily & 159 & $75.7 \%$ \\
\hline
\end{tabular}

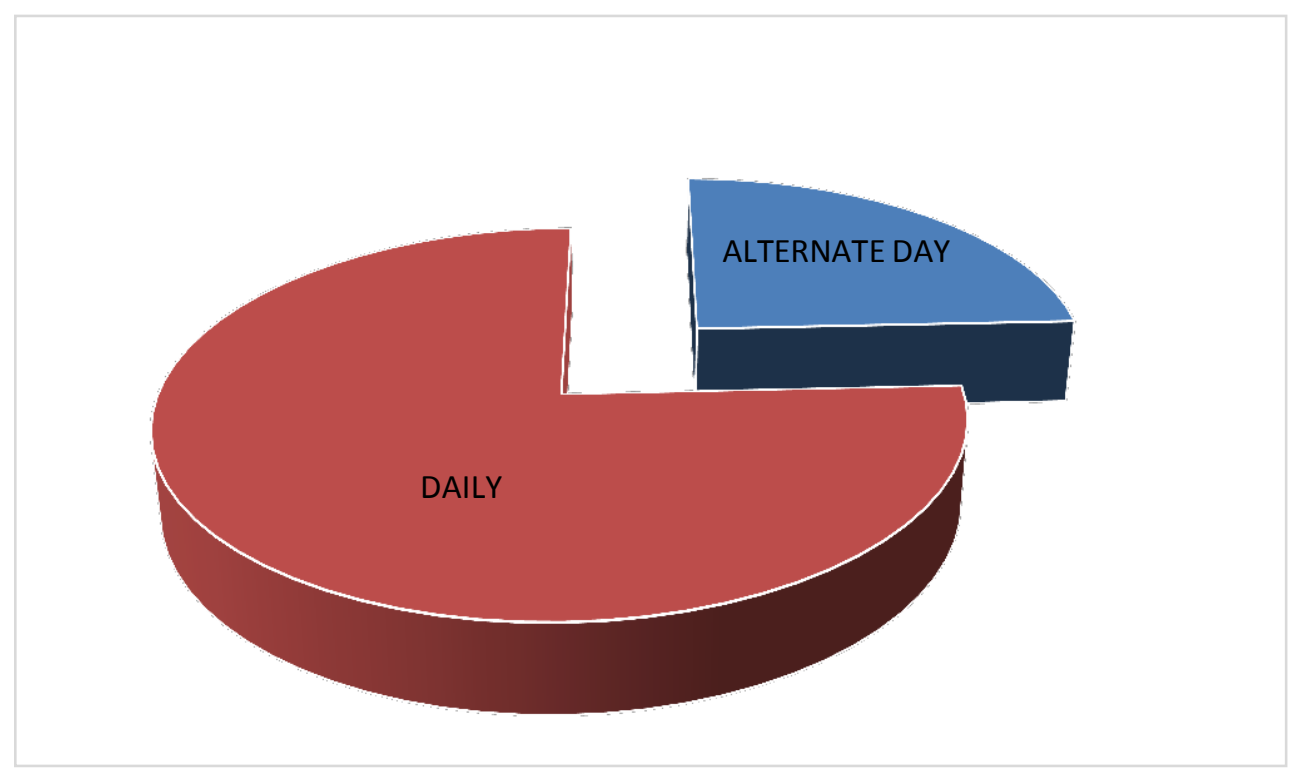

Frequency of change of dressing 
Type Of Surgery:-

In present series, out of 210 cases, 132 cases were operated as emergency surgery with percentage of $62.9 \%$

Type Of Surgery 1

\begin{tabular}{|l|l|l|}
\hline & EM/EL & Percent \\
\hline EL & 78 & $37.1 \%$ \\
\hline EM & 132 & $62.9 \%$ \\
\hline Total & 210 & $100 \%$ \\
\hline
\end{tabular}

Em: Emetgency, El:Elective

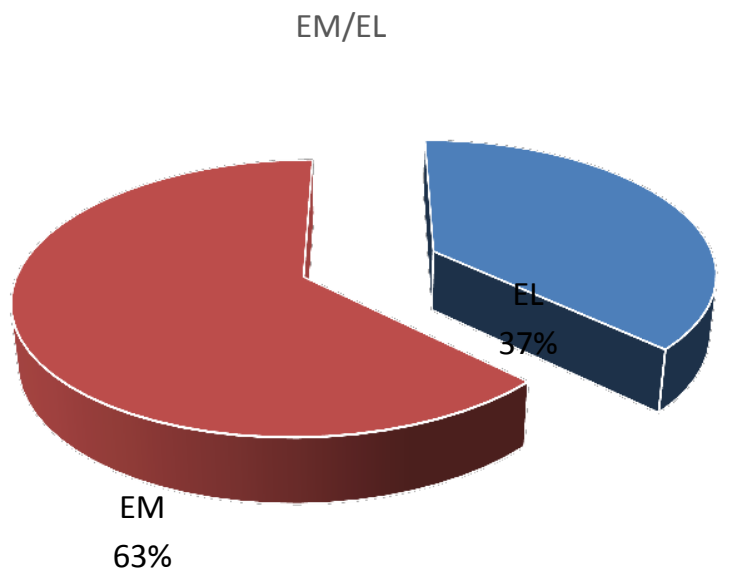

Em:Emetgency, El: Elective:-

Type of surgery:-

69 Cases in the series have undergone surgery which is classified as CC giving percentage of $32.9 \%$ and 30 cases have undergone clean contaminated giving percentage of $14.3 \%$.

Type Of Surgery 2

\begin{tabular}{|l|l|l|}
\hline Type of surgery & NO OF CASES & Percent \\
\hline CC & 69 & $32.9 \%$ \\
\hline CL & 45 & $21.4 \%$ \\
\hline CO & 30 & $14.3 \%$ \\
\hline D & 66 & $31.4 \%$ \\
\hline Total & 210 & $100 \%$ \\
\hline
\end{tabular}

Antibiotics given:

Tvpe of

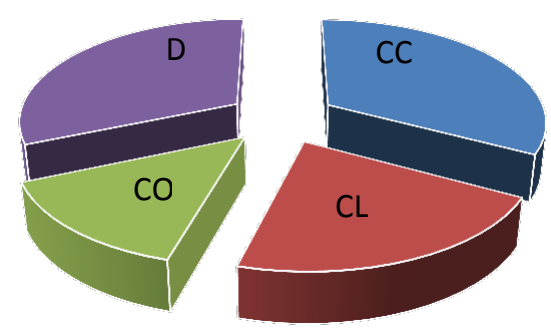


Out of 210 cases 195 cases $(92.90 \%)$ had received preoperative antibiotics.

Whereas, 15 cases $(7.10 \%)$ not received preoperative antibiotics and all case received postoperative antibiotics.

antibiotic

\begin{tabular}{|l|l|l|l|}
\hline & & Case & Column N \% \\
\hline PRE OP ANTIBIOTIC & NO & 15 & $7.10 \%$ \\
\hline POST OP ANTIBIOTIC & YES & 195 & $92.90 \%$ \\
\hline
\end{tabular}

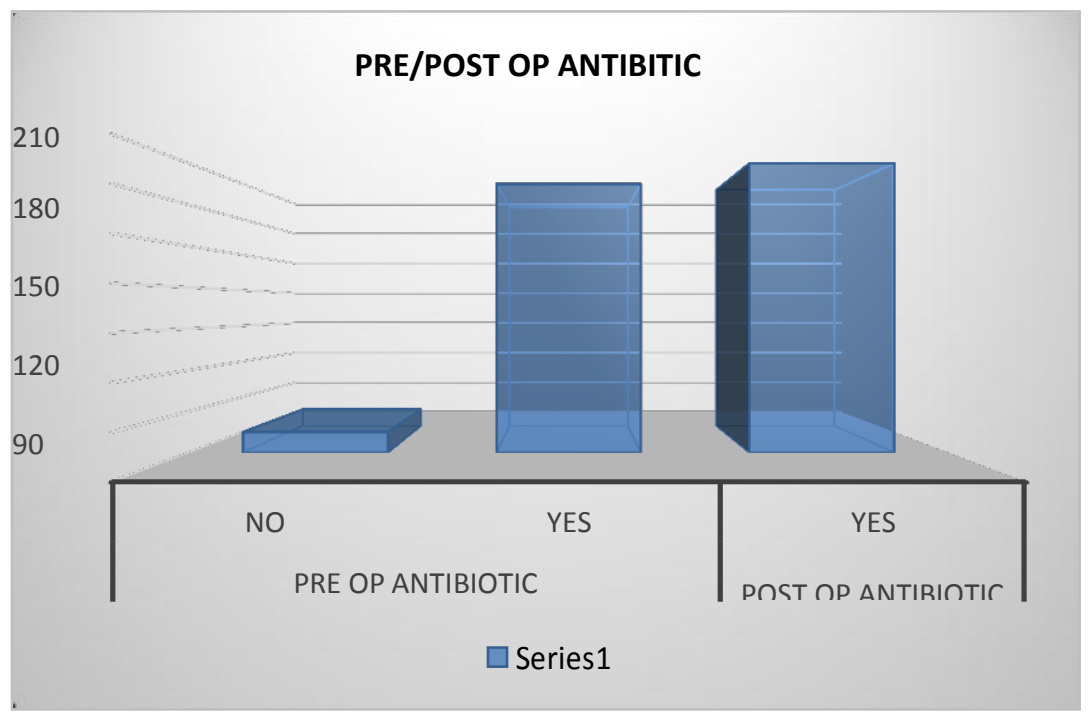

Preoperative preparation:-

In present series, 63 cases (30\%) had taken preoperative bath. Maximum patient's hair removal was done by shaving i.e. 159 case $(75.7 \%)$. Most of the affected cases were prepared <24 hrs before surgery i.e. 135 cases $(64.30 \%)$.

Showing Preoperative Preparation

\begin{tabular}{|l|l|l|l|}
\hline & & Count & Column N \% \\
\hline PRE OP BATH & NO & 147 & $70.00 \%$ \\
\hline & YES & 63 & $30.00 \%$ \\
\hline SHAVING/CLIPPING & CLIPPING & 51 & $24.30 \%$ \\
\hline & SHAVING & 159 & $75.70 \%$ \\
\hline SKIN PREPRATION & $<24$ & 135 & $64.30 \%$ \\
\hline & $>24$ & 75 & $35.70 \%$ \\
\hline INFECTED DAY & $2 \mathrm{nd}$ & 12 & $5.70 \%$ \\
\hline & $3 \mathrm{rd}$ & 177 & $84.30 \%$ \\
\hline & $4 \mathrm{th}$ & 21 & $10.00 \%$ \\
\hline
\end{tabular}



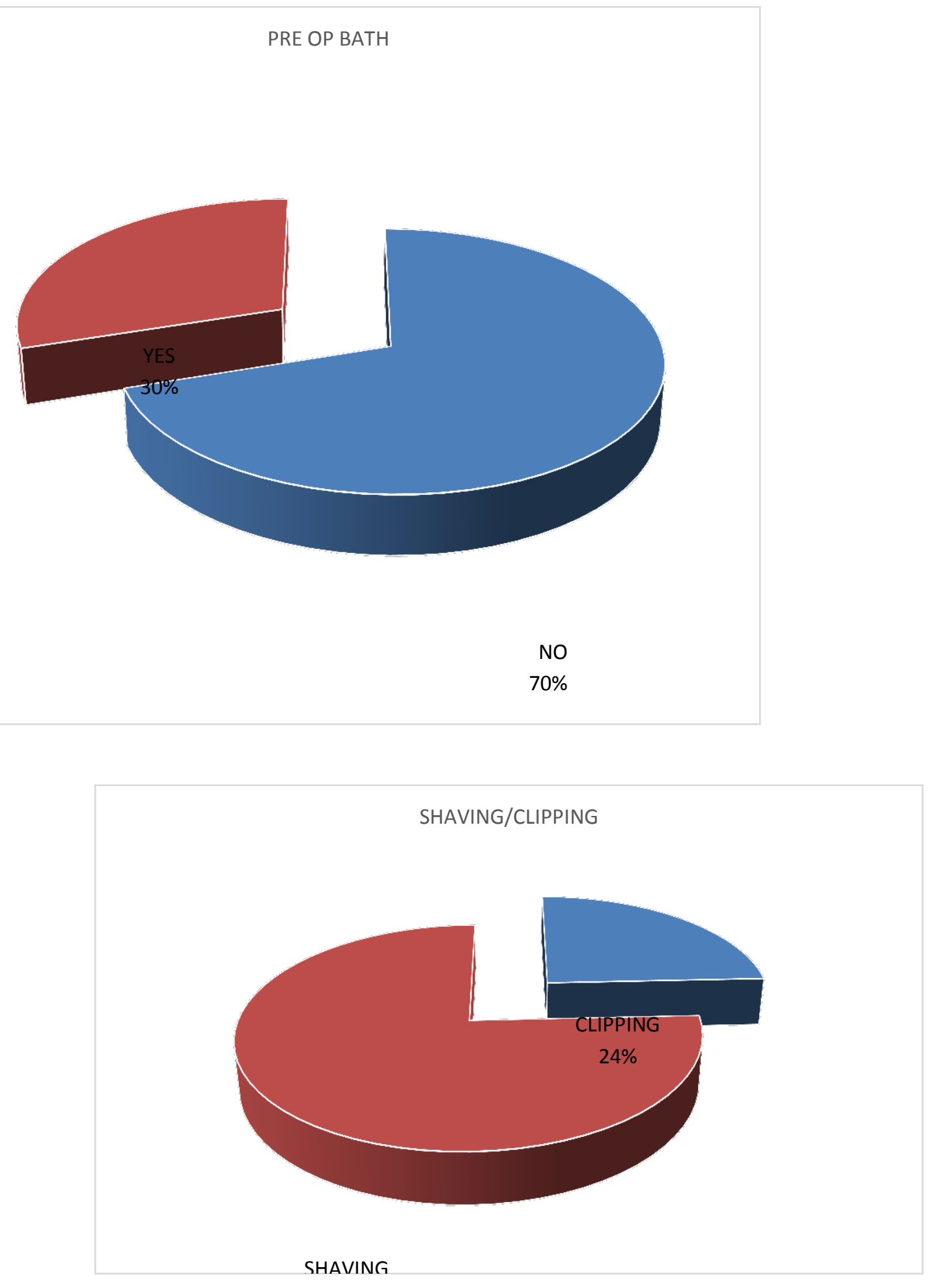

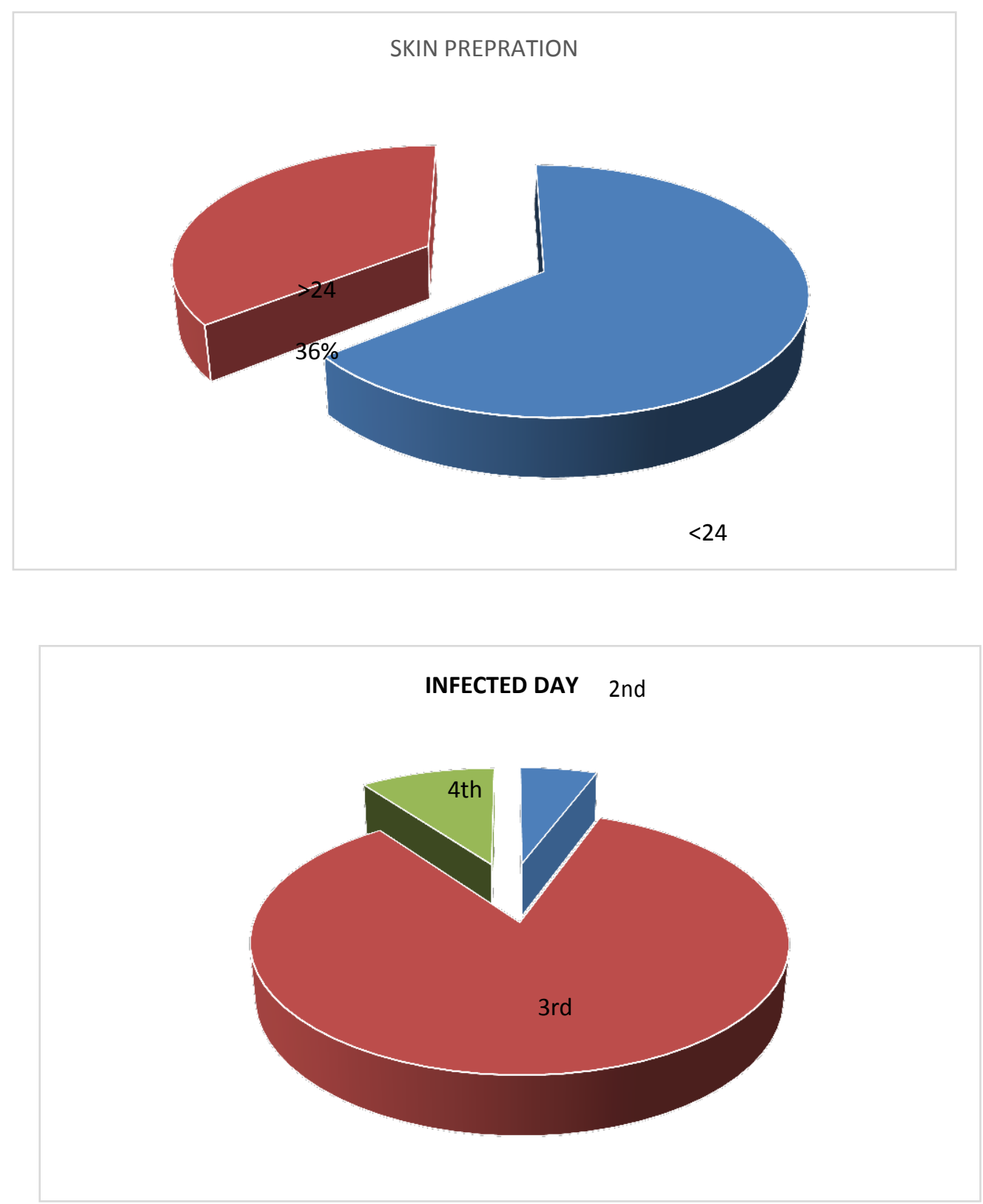

Microorganism:-

Most common microorganism encountered in present series is pseudomonas 72 cases $(34.30 \%)$. Least common micro organism is Staphylococcus i.e 6 case (2.90\%).

Table 10: Showing Microorganisms

\begin{tabular}{|l|l|l|l|}
\hline MICROORGANISM & Acinetobacter & $\mathbf{9}$ & $\mathbf{4 . 3 0 \%}$ \\
\hline & E.Coli & 36 & $17.10 \%$ \\
\hline & Kleibsiella & 36 & $17.10 \%$ \\
\hline & Proteus & 36 & $17.10 \%$ \\
\hline & Pseudomonas & 72 & $34.30 \%$ \\
\hline & Staphylococcus & 6 & $2.90 \%$ \\
\hline & Streptococci & 15 & $7.10 \%$ \\
\hline
\end{tabular}




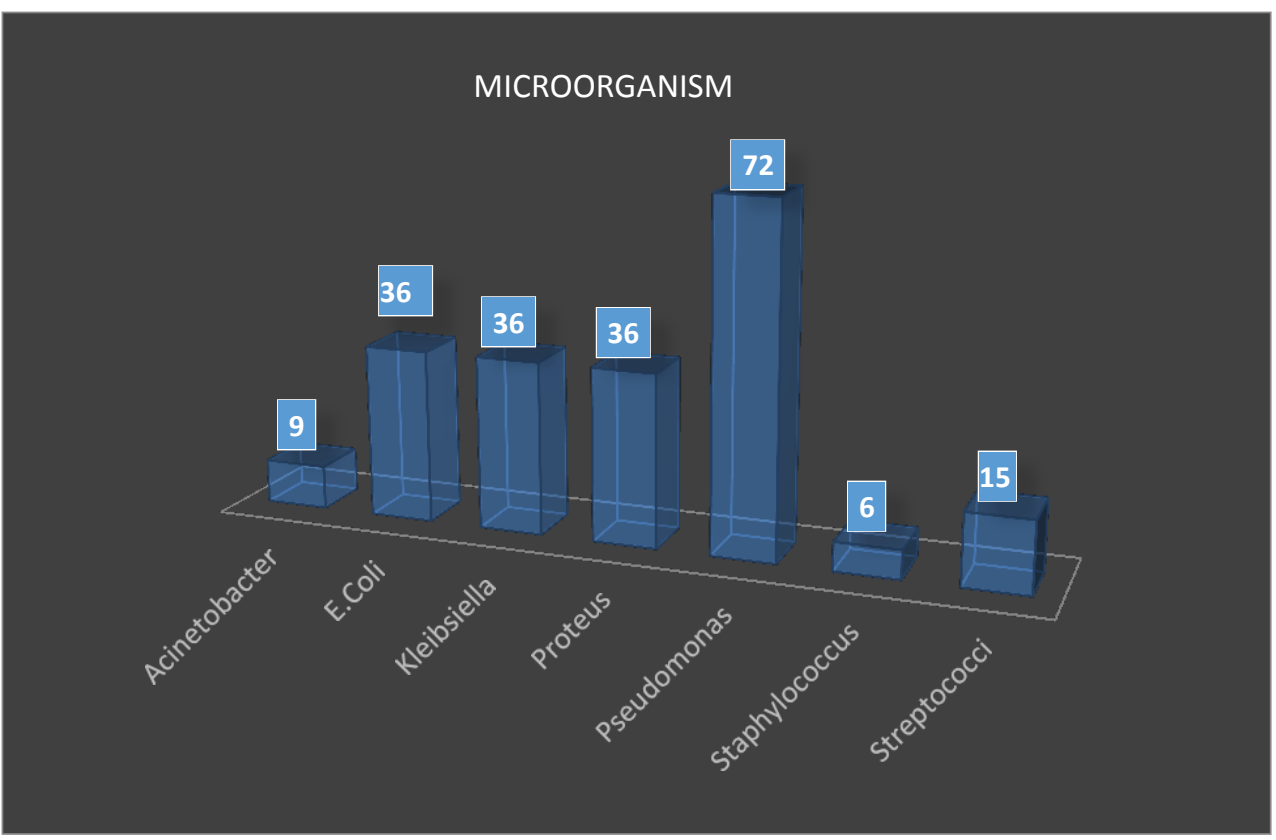

\section{Antibiotics:-}

Most sensitive antibiotic in present series is Amikacin. Other common Sensitive antibiotics are Amoxycillin, ChloramphenicoL,, Cefotaxime, AZITHROMYCIN.

Most resistant antibiotics are Colistin, other resistant imipeneam, ceftriaxone, amoxyclav

Table11:- Showing Antibiotic Sensitive And Resistant

\begin{tabular}{|l|l|l|l|}
\hline & SENSITIVIE/RESISTANT & Count & Column N \% \\
\hline Ampicillin & $\mathrm{R}$ & 93 & $44.30 \%$ \\
\hline & $\mathrm{S}$ & $\mathbf{1 1 7}$ & $55.70 \%$ \\
\hline Amoxycillin & $\mathrm{R}$ & 66 & $31.40 \%$ \\
\hline Amikacin & $\mathrm{S}$ & $14 \mathbf{4}$ & $68.60 \%$ \\
\hline & $\mathrm{R}$ & 32 & $20.00 \%$ \\
\hline Chloramphenicol & $\mathrm{S}$ & $\mathbf{1 7 8}$ & $80.00 \%$ \\
\hline & $\mathrm{R}$ & 63 & $30.00 \%$ \\
\hline Cefotaxime & $\mathrm{S}$ & $\mathbf{1 4 7}$ & $70.00 \%$ \\
\hline & $\mathrm{R}$ & 84 & $40.00 \%$ \\
\hline Ciprofloxacin & $\mathrm{S}$ & $\mathbf{1 2 6}$ & $60.00 \%$ \\
\hline & $\mathrm{R}$ & 102 & $48.60 \%$ \\
\hline Ceftriaxone & $\mathrm{S}$ & $\mathbf{1 0 8}$ & $51.40 \%$ \\
\hline & $\mathrm{R}$ & 129 & $61.40 \%$ \\
\hline Doxycycline & $\mathrm{S}$ & $\mathbf{8 1}$ & $38.60 \%$ \\
\hline & $\mathrm{R}$ & 99 & $47.10 \%$ \\
\hline Erythromycin & $\mathrm{S}$ & $\mathbf{1 1 1}$ & $52.90 \%$ \\
\hline & $\mathrm{R}$ & 114 & $54.30 \%$ \\
\hline Gentamycin & $\mathrm{S}$ & $\mathbf{9 6}$ & $45.70 \%$ \\
\hline & $\mathrm{R}$ & 99 & $47.10 \%$ \\
\hline Piperacillin & $\mathrm{S}$ & $\mathbf{1 1 1}$ & $52.90 \%$ \\
\hline & $\mathrm{R}$ & 105 & $50.00 \%$ \\
\hline AZITHROMYCIN & $\mathrm{S}$ & $\mathbf{1 0 5}$ & $50.00 \%$ \\
\hline & $\mathrm{R}$ & 93 & $44.30 \%$ \\
\hline AMOXYCLAV & $\mathrm{S}$ & $\mathbf{1 1 7}$ & $55.70 \%$ \\
\hline & $\mathrm{R}$ & 126 & $60.00 \%$ \\
\hline
\end{tabular}




\begin{tabular}{|l|l|l|l|}
\hline & S & $\mathbf{8 4}$ & $40.00 \%$ \\
\hline IMIPENEM & $\mathrm{R}$ & 126 & $60.00 \%$ \\
\hline & $\mathrm{S}$ & $\mathbf{8 4}$ & $40.00 \%$ \\
\hline SULBACTUM & $\mathrm{R}$ & 120 & $57.10 \%$ \\
\hline & $\mathrm{S}$ & $\mathbf{9 0}$ & $42.90 \%$ \\
\hline Colistin & $\mathrm{R}$ & 153 & $72.90 \%$ \\
\hline & $\mathrm{S}$ & $\mathbf{5 7}$ & $27.10 \%$ \\
\hline
\end{tabular}

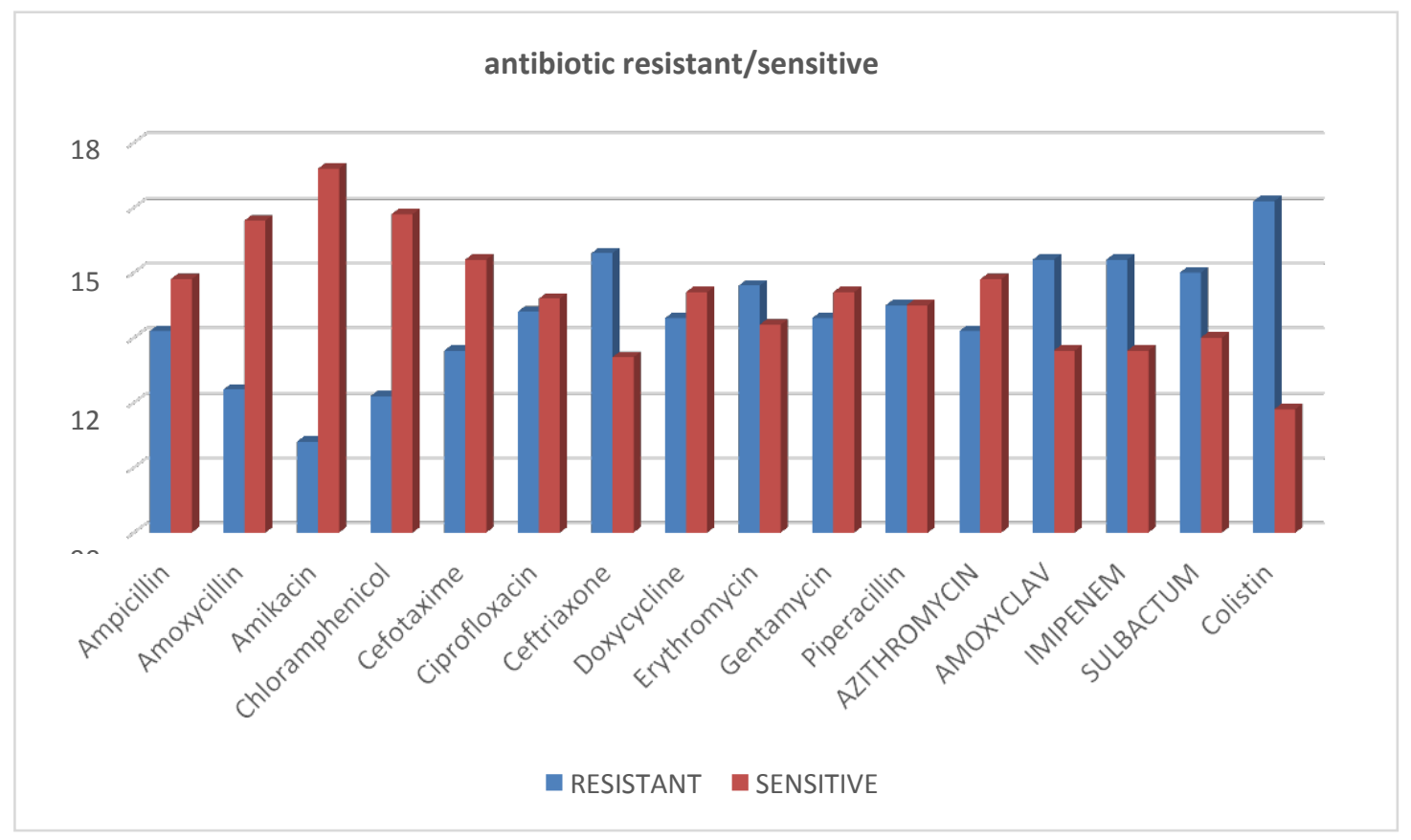

\section{Discussion:-}

The present study was conducted in YENEPOYA MEDICAL COLLEGE AND HOSPITAL . This is cross sectional type of study.

Microorganism:

Most common organism encountered in postoperative wound infection in this study is PSEUDOMONAS, in 72 cases accounting for $34.30 \%$. the second common organism in this study is E.Coli, in 36 cases accounting for $17.10 \%$. The least common organism was STAPHYLOCOCCUS and ACINETOBACTER.

\begin{tabular}{|l|l|l|l|}
\hline AUTHOR & BHIRUD et al & TRIPATHY et al & MY STUDY \\
\hline -ommonest Organism & E coli & PSEUDOMONAS & PSEUDOMONAS \\
\hline
\end{tabular}

Tripathy et al, shows PSEUDOMONAS as commonest organism inpostoperative wound infection. Our values matches with the observations by tripathy et al.

Bhirud et al, shows that Ecoli as predominant microorganism isolated ie $40 \%$ and $2^{\text {nd }}$ most common organism 
Antibiotics sensitivity and resistance

\begin{tabular}{|l|l|l|l|}
\hline Author & Kowl et al101 & Tripathy & My study \\
\hline Antibiotic & Cloxacillin & Co-trimoxazole & Amikacin \\
\hline Sensitive & Cotrimoxazole & Chloramphenicol & Amoxycillin, \\
\hline & Chloramphenicol & Gentamicin & ChloramphenicoL, \\
\hline & Cephaloridine & & Cefotaxime, \\
\hline & Gentamicin & & azithromycin. \\
\hline & Kanamycin & & \\
\hline Antibiotic & Piperacillin & Penicillin & Colistin \\
\hline & Ceftriaxone & Tetracycline & imipenem, \\
\hline & Ampicillin & Ampicillin & ceftriaxone, \\
\hline & & Erythromycin & amoxyclav \\
\hline
\end{tabular}

In our study the common sensitive antibiotics are Amikacin, Amoxycillin, ChloramphenicoL, Cefotaxime, azithromycin. The common resistant antibiotics are Colistin imipenem, Ceftriaxone, amoxyclav. The reason for sensitivity of the antibiotics in our series is probably due to their broad spectrum and less routine use due to unavailability of oral preparation,cost. Therefore less commonly prescribed as outpatient. The reason for resistance ofantibiotics in our series is probably due to their more common use in outpatient department and indoor patients for prolonged period.

Kowli et al, shows gentamycin, Cloxacillin, cotrimoxazole Chloramphenicol more sensitive antibiotic postoperatively for gram positive aerobes and cephaloridine, Gentamycin, Kanamycin sensitive against gram negative aerobes.

Tripathy et al, observed that organisms were less sensitive to penicillin, tetracycline, ampicillin and erythromycin in that order of descending magnitude as compared to cotrimoxazole, gentamycin and chloramphenicol.

Surgery (emergency/elective):

\begin{tabular}{|l|l|l|}
\hline Authors & BHIRUD et al & My study \\
\hline No. of elective & 23 & 78 \\
\hline Cases operated & & \\
\hline Percentage of infected & & \\
\hline cases in elective surgeries & $30.7 \%$ & $37.1 \%$ \\
\hline No. of emergency cases & 52 & 132 \\
\hline Operated & & \\
\hline percentage of infected cases in & & \\
\hline emergency surgeries & $69.3 \%$ & $62.9 \%$ \\
\hline
\end{tabular}

In present study the number of cases with postoperative wound infection in elective surgery are 78 accounting for $37.1 \%$ and for emergency surgery are 132 cases accounting for $62.9 \%$. the reason of postoperative would infection being most common in emergency surgery is most probably that the most patients being operated for emergency surgery had hollow viscus perforation with contamination of peritoneal cavity causing contamination of wound.

Bhirud et al shows that 52 patients were operated as emergency surgery with wound infection rate of $69.3 \%$ versus 23 patients were operated as elective surgery with wound infection rate of $30.7 \%$. so this study results matches with our study which shows that post operative wound infection rate is more in emergency surgery.

Preoperative preparation:-

\begin{tabular}{|l|l|l|}
\hline Pre op preparation & Bhirud et al & My study \\
\hline Bath & 17 & 63 \\
\hline Shaving Clipping & 57 & 159 \\
& 18 & 51 \\
\hline$<24$ & 27 & 135 \\
$>24$ & 48 & 75 \\
\hline
\end{tabular}


In present study, 159cases were prepared by shaving accounting for $76 \%$. whereas 51 cases were prepared by clipping accounting for $24 \%$. The reason for this is probably that shaving caused minor trauma and abrasion where bacteria colonized leading to more postoperative wound infection.

In this study, 63 cases have taken preoperation bath accounting for $30 \%$ cases who have taken preoperative bath are less as compared to cases who have not taken bath. The reason for this is probably, preoperative bath reduced the microbiological flora over skin.

In the present series, 75 cases were prepared $>24 \mathrm{hrs}$ before the surgery accounting for $36 \%$ whereas 135 cases were prepared $<24 \mathrm{hrs}$ before surgery, accounting for $64 \%$. The reason for this is probably, more gap between skin preparation and surgery caused increased microbiological flora locally.

Bhirud et al study show 57 cases shaving and 18 cases clipping, 17 cases taken bath, 48 cases were prepared < 24 hrs before surgery 27 cases prepared $>24$ hrs before the surgery.

Type of surgery

\begin{tabular}{|l|l|l|l|}
\hline Type of operation & Bhirud et al & My study & Percentage \\
\hline Clean & 4 & 45 & $21.4 \%$ \\
\hline Clean contaminated & 7 & 69 & $32.9 \%$ \\
\hline Contaminated & 16 & 30 & $14.3 \%$ \\
\hline Dirty & 47 & 66 & $31.4 \%$ \\
\hline
\end{tabular}

In present study, the wound infection rate for clean, clean contaminated, contaminated and dirty cases is $21.4 \%$, $32.9 \%, 14.3 \%$ and $31.4 \%$ respectively. The reason for this increasing rate of wound infection is probably, increasing contamination during surgery.

To reduce ssi:-

The principle of disinfection should be followed meticulous.

While operating ACUTE APPENDICITIS extra care should be taken ensure that the operating field should not be contaminated with pus.

In obstructed hernia toxic fluid should let out first from fundus of sac.

\section{Conclusion:-}

* In the study conducted in YENEPOYA MEDICAL COLLEGE AND HOSPITAL. my conclusion is-

* Out of 210 cases 132 cases were operated as emergency surgery accounting for $62.90 \%$.

* 69 cases out of 210 have undergone surgery which is classified as clean contaminated accounting for $32.90 \%$.

- Out of 210 cases 195(92.90\%) cases received preoperative antibiotics, 5\% not received preoperative and all cases resived postoperative antibiotics.63(30\%) cases had preoperative bath. 159(75.70\%) cases, hair removal was done by shaving,75(35.70\%) cases skin was prepared $>24$ hrs before surgery and $135(64.30 \%)$ cases skin was prepared 24 hrs before surgery.

* In 34.30\%(72) cases Pseudomonas was the micro-organism found on culture.

* More sensitive antibiotics are Amikacin, Amoxycillin, ChloramphenicoL, Cefotaxime.

* More resistant antibiotics are Colistin, IMIPENEM, Ceftriaxone, amoxyclav 


\begin{tabular}{|c|c|c|c|c|c|c|c|c|c|c|c|c|c|c|c|c|}
\hline \multicolumn{17}{|c|}{$\begin{array}{l}\mathbf{M} \\
\mathbf{A}\end{array}$} \\
\hline NAM & $\mathbf{A}$ & S & IP & DIA & $\mathbf{E}$ & $T$ & $\mathbf{P}$ & SHAV & SKI & IN & $\mathbf{F}$ & ER & DIS & DIS & DR & MIC \\
\hline THA & 1 & $M$ & 17 & $\mathrm{AA}$ & $\mathrm{E}$ & $\mathrm{C}$ & $\mathrm{N}$ & CLIP & $<24$ & $3 \mathrm{rd}$ & - & + & + & Puru & $\mathrm{DA}$ & E.Coli \\
\hline $\mathrm{BEEF}$ & 5 & $\mathrm{~F}$ & 17 & INT & $\mathrm{E}$ & $\mathrm{C}$ & $\mathrm{N}$ & CLIP & $<24$ & 4th & + & - & - & NIL & Alt & Pseudo \\
\hline MUZ & 3 & $\mathrm{M}$ & 17 & $\mathrm{AA}$ & $\mathrm{E}$ & $\mathrm{C}$ & $\mathrm{Y}$ & SHA & $>24$ & $3 \mathrm{rd}$ & + & + & + & Puru & DA & Proteus \\
\hline THO & 8 & $\mathrm{M}$ & 17 & $\mathrm{IH}$ & E & $\mathrm{C}$ & $\mathrm{Y}$ & SHA & $>24$ & $3 \mathrm{rd}$ & - & + & - & NIL & Alt & E.Coli \\
\hline KHA & 5 & $\mathrm{~F}$ & 17 & $\mathrm{CA}$ & $\mathrm{E}$ & $\mathrm{C}$ & $\mathrm{N}$ & SHA & $>24$ & 2 nd & - & + & + & Sero & $\mathrm{DA}$ & Proteus \\
\hline NASE & 1 & $\mathrm{~F}$ & 17 & $\mathrm{AA}$ & $\mathrm{E}$ & $\mathrm{C}$ & $\mathrm{N}$ & CLIP & $<24$ & $3 \mathrm{rd}$ & + & + & + & Sero & $\mathrm{DA}$ & Pseudo \\
\hline FAIZ & 1 & $\mathrm{M}$ & 19 & $\mathrm{AP}$ & $\mathrm{E}$ & $\mathrm{D}$ & $\mathrm{N}$ & SHA & $<24$ & $3 \mathrm{rd}$ & + & - & + & Puru & $\mathrm{DA}$ & Pseudo \\
\hline MUM & 4 & $\mathrm{~F}$ & 24 & $\mathrm{CA}$ & $\mathrm{E}$ & $\mathrm{C}$ & $\mathrm{Y}$ & CLIP & $<24$ & 3 rd & + & - & - & NIL & Alt & KleIN \\
\hline NITH & 1 & $\mathrm{M}$ & 19 & $\mathrm{HY}$ & $\mathrm{E}$ & $\mathrm{C}$ & $\mathrm{N}$ & CLIP & $>24$ & 4th & - & - & + & Sero & $\mathrm{DA}$ & Strento \\
\hline BHAS & 5 & $M$ & 20 & INT & $\mathrm{E}$ & $\mathrm{C}$ & $\mathrm{Y}$ & SHA & $>24$ & $3 \mathrm{rd}$ & + & + & + & Puru & $\mathrm{DA}$ & E.Coli \\
\hline ALI.P & 4 & $\mathrm{M}$ & 21 & UH & $\mathrm{E}$ & $\mathrm{C}$ & $\mathrm{N}$ & SHA & $>24$ & 3 rd & - & + & - & NIL & Alt & Pseudo \\
\hline SAM & 2 & $\mathrm{M}$ & 18 & $\mathrm{AA}$ & $\mathrm{E}$ & $\mathrm{C}$ & $\mathrm{N}$ & CLIP & $<24$ & $3 \mathrm{rd}$ & - & & + & Puru & $\mathrm{DA}$ & E.Coli \\
\hline AMA & 4 & $\mathrm{M}$ & 21 & IP & $\mathrm{E}$ & $\mathrm{D}$ & $\mathrm{N}$ & CLIP & $<24$ & 2 nd & - & - & + & Sero & $\mathrm{DA}$ & KleIN \\
\hline SHA & 3 & $\mathrm{~F}$ & 16 & $\mathrm{AP}$ & $\mathrm{E}$ & $\mathrm{D}$ & $\mathrm{N}$ & SHA & $<24$ & 2 nd & - & - & + & Puru & $\mathrm{DA}$ & Pseudo \\
\hline SAL & 1 & $M$ & 18 & AA & $\mathrm{E}$ & $\mathrm{C}$ & $\mathrm{N}$ & SHA & $<24$ & $3 \mathrm{rd}$ & - & + & - & NIL & Alt & Acinet \\
\hline JOSE & 7 & M & 19 & HY & $\mathrm{E}$ & $\mathrm{C}$ & $\mathrm{Y}$ & SHA & $>24$ & $3 \mathrm{rd}$ & + & - & + & Sero & DA & E.Coli \\
\hline VAS & 6 & $\mathrm{M}$ & 15 & $\mathbf{A P}$ & $\mathrm{E}$ & $\mathrm{D}$ & $\mathrm{N}$ & SHA & $<24$ & $3 \mathrm{rd}$ & & - & + & Puru & $\mathrm{DA}$ & KleIN \\
\hline DIJA & 2 & $\mathrm{M}$ & 21 & DU & $\mathrm{E}$ & $\mathrm{C}$ & $\mathrm{N}$ & SHA & $<24$ & 2 nd & - & - & + & Sero & $\mathrm{DA}$ & E.Coli \\
\hline VAIS & 2 & $\mathrm{~F}$ & 18 & AA & E & $\mathrm{C}$ & $\mathrm{Y}$ & SHA & $<24$ & $3 \mathrm{rd}$ & - & + & - & NIL & Alt & Pseudo \\
\hline ANN & 7 & $\mathrm{~F}$ & 24 & INT & $E$ & $\mathrm{C}$ & $\mathrm{Y}$ & SHA & $>24$ & $3 \mathrm{rd}$ & + & + & + & Sero & $\mathrm{DA}$ & Strepto \\
\hline SUHE & 3 & $\mathrm{M}$ & 21 & $\mathrm{DU}$ & $\mathrm{E}$ & $\mathrm{D}$ & $\mathrm{N}$ & SHA & $<24$ & $3 \mathrm{rd}$ & - & - & + & Sero & $\mathrm{DA}$ & Pseudo \\
\hline JOSE. & 6 & $\mathrm{M}$ & 20 & INT & E & $\mathrm{C}$ & $\mathrm{N}$ & CLIP & $<24$ & $3 \mathrm{rd}$ & + & - & - & NIL & Alt & KleIN \\
\hline SAEI & 2 & $\mathrm{M}$ & 19 & $\mathrm{AP}$ & $E$ & $\mathrm{D}$ & $\mathrm{N}$ & CLIP & $<24$ & $3 \mathrm{rd}$ & + & - & + & Puru & $\mathrm{DA}$ & E. Coli \\
\hline NISH & 2 & $\mathrm{~F}$ & 19 & $\mathrm{AA}$ & E & $\mathrm{C}$ & $\mathrm{N}$ & CLIP & $<24$ & $3 \mathrm{rd}$ & + & + & - & Puru & $\mathrm{DA}$ & Proteus \\
\hline JAME & 4 & $M$ & 19 & AP & $\mathrm{E}$ & $\mathrm{D}$ & $\mathrm{N}$ & SHA & $<24$ & $3 \mathrm{rd}$ & + & - & + & Puru & $\mathrm{DA}$ & Pseudo \\
\hline IDDI & 4 & $\mathrm{M}$ & 21 & $\mathrm{UH}$ & $E$ & $\mathrm{C}$ & $Y$ & SHA & $>24$ & $3 \mathrm{rd}$ & + & - & - & NIL & Alt & Pseudo \\
\hline sumat & 7 & $\mathrm{~F}$ & 24 & $\mathrm{CA}$ & E & $\mathrm{C}$ & $\mathrm{Y}$ & SHA & $>24$ & $3 \mathrm{rd}$ & + & + & + & Puru & DA & KleIN \\
\hline MAD & 5 & $M$ & 16 & $\mathrm{IH}$ & $\mathrm{E}$ & $\mathrm{C}$ & $\mathrm{Y}$ & SHA & $>24$ & $3 \mathrm{rd}$ & - & - & + & Sero & $\mathrm{DA}$ & Pseudo \\
\hline AYS & 2 & $\mathrm{~F}$ & 20 & $\mathrm{AA}$ & $\mathrm{E}$ & $\mathrm{C}$ & $\mathrm{N}$ & CLIP & $<24$ & $3 \mathrm{rd}$ & + & - & + & Sero & $\mathrm{DA}$ & Pseudo \\
\hline $\mathrm{ACH}$ & 6 & $M$ & 21 & INT & E & $\mathrm{C}$ & $\mathrm{N}$ & CLIP & $<24$ & $3 \mathrm{rd}$ & - & - & + & Sero & $\mathrm{DA}$ & Proteus \\
\hline NIZA & 6 & $M$ & 17 & DU & E & $\mathrm{D}$ & $\mathrm{N}$ & SHA & $<24$ & $3 \mathrm{rd}$ & - & + & + & Sero & $\mathrm{DA}$ & E.Coli \\
\hline NAW & 2 & $\mathrm{M}$ & 23 & $\mathrm{DU}$ & $\mathrm{E}$ & $\mathrm{D}$ & $\mathrm{N}$ & SHA & $<24$ & $3 \mathrm{rd}$ & + & & & NIL & Alt & KleIN \\
\hline LAKS & 7 & M & 25 & $\mathrm{CA}$ & $\mathrm{E}$ & $\mathrm{C}$ & $\mathrm{Y}$ & SHA & $>24$ & 4th & - & + & + & Puru & DA & KleIN \\
\hline RIHA & 3 & $\mathrm{~F}$ & 24 & DR & $\mathrm{E}$ & $\mathrm{C}$ & $\mathrm{N}$ & SHA & $>24$ & 4th & + & - & + & Sero & DA & Proteus \\
\hline RAO & 3 & $\mathrm{M}$ & 24 & $\mathrm{HY}$ & $E$ & $\mathrm{C}$ & $\mathrm{Y}$ & SHA & $>24$ & $3 \mathrm{rd}$ & + & - & - & NIL & Alt & Strento \\
\hline $\mathrm{CHA}$ & 5 & $M$ & 20 & IP & E & $\mathrm{D}$ & $\mathrm{N}$ & CLIP & $<24$ & $3 \mathrm{rd}$ & - & - & + & Sero & $\mathrm{DA}$ & KleIN \\
\hline KUN & 7 & $\mathrm{M}$ & 17 & INT & $\mathrm{E}$ & $\mathrm{C}$ & $\mathrm{N}$ & SHA & $<24$ & $3 \mathrm{rd}$ & & + & + & Puru & $\mathrm{DA}$ & E. Coli \\
\hline MUM & 1 & $\mathrm{M}$ & 23 & $\mathrm{AA}$ & $\mathrm{E}$ & $\mathrm{C}$ & $\mathrm{N}$ & SHA & $<24$ & 4th & + & - & - & NIL & Alt & Proteus \\
\hline ALIM & 5 & $\mathrm{~F}$ & 22 & $\mathrm{AP}$ & E & D & $\mathrm{N}$ & SHA & $<24$ & $3 \mathrm{rd}$ & - & - & + & Sero & DA & Pseudo \\
\hline $\mathrm{CHE}$ & 7 & $\mathrm{M}$ & 23 & $\mathrm{DU}$ & $\mathrm{E}$ & $\mathrm{D}$ & $\mathrm{N}$ & SHA & $<24$ & $3 \mathrm{rd}$ & - & - & + & Puru & $\mathrm{DA}$ & Proteus \\
\hline THO & 5 & $\mathrm{M}$ & 23 & IP & $\mathrm{E}$ & $\mathrm{D}$ & $\mathrm{N}$ & SHA & $<24$ & $3 \mathrm{rd}$ & - & - & + & Sero & $\mathrm{DA}$ & Pseudo \\
\hline SURE & 4 & $\mathrm{M}$ & 20 & INT & E & $\mathrm{C}$ & $\mathrm{N}$ & SHA & $<24$ & $3 \mathrm{rd}$ & + & - & & NIL & Alt & KleIN \\
\hline DHA & 3 & $\mathrm{M}$ & 17 & $\mathrm{CA}$ & $\mathrm{E}$ & $\mathrm{C}$ & $\mathrm{Y}$ & CLIP & $>24$ & $3 \mathrm{rd}$ & + & - & + & Sero & $\mathrm{DA}$ & Acinet \\
\hline $\mathrm{ABD}$ & 3 & $\mathrm{M}$ & 17 & $\mathrm{AA}$ & $\mathrm{E}$ & $\mathrm{C}$ & $\mathrm{N}$ & SHA & $<24$ & $3 \mathrm{rd}$ & + & + & + & Puru & $\mathrm{DA}$ & Staphvl \\
\hline JAME & 4 & M & 19 & IP & E & $\mathrm{D}$ & $\mathrm{N}$ & SHA & $<24$ & $3 \mathrm{rd}$ & & + & + & Sero & DA & Pseudo \\
\hline SHA & 5 & $\mathrm{~F}$ & 24 & $\mathrm{CA}$ & $\mathrm{E}$ & $\mathrm{C}$ & $\mathrm{Y}$ & SHA & $<24$ & $3 \mathrm{rd}$ & + & - & + & Sero & $\mathrm{DA}$ & Proteus \\
\hline SIDDI & 5 & $\mathrm{M}$ & 24 & INT & $\mathrm{E}$ & $\mathrm{C}$ & $\mathrm{N}$ & SHA & $<24$ & $3 \mathrm{rd}$ & + & + & & NIL & Alt & E. Coli \\
\hline ANEE & 3 & $\mathrm{~F}$ & 10 & $\mathrm{AP}$ & $\mathrm{E}$ & $\mathrm{D}$ & $\mathrm{N}$ & SHA & $<24$ & $3 \mathrm{rd}$ & - & - & + & Sero & $\mathrm{DA}$ & Pseudo \\
\hline SAOI & 3 & $\mathrm{M}$ & 24 & $\mathrm{HY}$ & $\mathrm{E}$ & $\mathrm{C}$ & $\mathrm{Y}$ & SHA & $>24$ & $3 \mathrm{rd}$ & + & - & + & Puru & DA & Proteus \\
\hline $\mathrm{MOH}$ & 4 & $\mathrm{M}$ & 21 & $\mathrm{AA}$ & $\mathrm{E}$ & $\mathrm{C}$ & $\mathrm{Y}$ & SHA & $>24$ & $3 \mathrm{rd}$ & & - & + & Sero & $\mathrm{DA}$ & E. Coli \\
\hline RAJA & 4 & $\mathrm{M}$ & 21 & DU & E & $\mathrm{D}$ & $\mathrm{N}$ & SHA & $<24$ & $3 \mathrm{rd}$ & + & - & - & NIL & Alt & KleIN \\
\hline VISH & 5 & $\mathrm{M}$ & 18 & INT & $\mathrm{E}$ & $\mathrm{C}$ & $\mathrm{Y}$ & SHA & $>24$ & $3 \mathrm{rd}$ & & - & + & Sero & $\mathrm{DA}$ & Pseudo \\
\hline TABB & 3 & $\mathrm{~F}$ & 20 & $\mathrm{AA}$ & $\mathrm{E}$ & $\mathrm{C}$ & $\mathrm{N}$ & CLIP & $<24$ & $3 \mathrm{rd}$ & - & + & + & Puru & $\mathrm{DA}$ & Strepto \\
\hline GOP & 6 & $M$ & 18 & $\mathrm{IH}$ & $\mathrm{E}$ & $\mathrm{C}$ & $\mathrm{Y}$ & SHA & $>24$ & $3 \mathrm{rd}$ & & - & + & Puru & $\mathrm{DA}$ & KleIN \\
\hline JAYA & 3 & $\mathrm{M}$ & 22 & $\mathrm{AP}$ & $\mathrm{E}$ & $\mathrm{D}$ & $\mathrm{N}$ & SHA & $<24$ & 4th & + & - & - & NIL & Alt & Pseudo \\
\hline $\mathrm{MOH}$ & 5 & M & 24 & $\mathrm{CA}$ & $\mathrm{E}$ & $\mathrm{C}$ & $\mathrm{Y}$ & SHA & $>24$ & $3 \mathrm{rd}$ & + & - & + & Sero & $\mathrm{DA}$ & Pseudo \\
\hline UMA & 7 & $\mathrm{M}$ & 17 & INT & $\mathrm{E}$ & $\mathrm{C}$ & $\mathrm{N}$ & SHA & $<24$ & $3 \mathrm{rd}$ & & - & + & Sero & $\mathrm{DA}$ & Proteus \\
\hline PARV & 7 & $\mathrm{~F}$ & 15 & $\mathrm{DU}$ & $\mathrm{E}$ & $\mathrm{D}$ & $\mathrm{N}$ & SHA & $<24$ & $3 \mathrm{rd}$ & + & - & $T$ & NIL & Alt & Staphvl \\
\hline BEN & 4 & $M$ & 22 & $\mathrm{AP}$ & E & $\mathrm{D}$ & $\mathrm{N}$ & SHA & $<24$ & $3 \mathrm{rd}$ & + & + & + & Puru & DA & Proteus \\
\hline REH & 3 & $\mathrm{~F}$ & 19 & $\mathrm{CA}$ & $\mathrm{E}$ & $\mathrm{C}$ & $\mathrm{N}$ & SHA & $<24$ & $3 \mathrm{rd}$ & & + & + & Sero & $\mathrm{DA}$ & Pseudo \\
\hline MAR & 2 & $\mathrm{~F}$ & 21 & $\mathrm{AA}$ & $\mathrm{E}$ & $\mathrm{C}$ & $\mathrm{N}$ & SHA & $<24$ & $3 \mathrm{rd}$ & + & - & + & Sero & $\mathrm{DA}$ & Pseudo \\
\hline $\mathrm{MOH}$ & 1 & $M$ & 18 & AA & E & $\mathrm{C}$ & $\mathrm{Y}$ & SHA & $>24$ & 3 rd & + & + & - & NIL & $\mathrm{DA}$ & KleIN \\
\hline SIDDI & 3 & M & 15 & IP & E & D & $\mathrm{N}$ & SHA & $<24$ & $3 \mathrm{rd}$ & & & + & Puru & $\mathrm{DA}$ & Pseudo \\
\hline
\end{tabular}




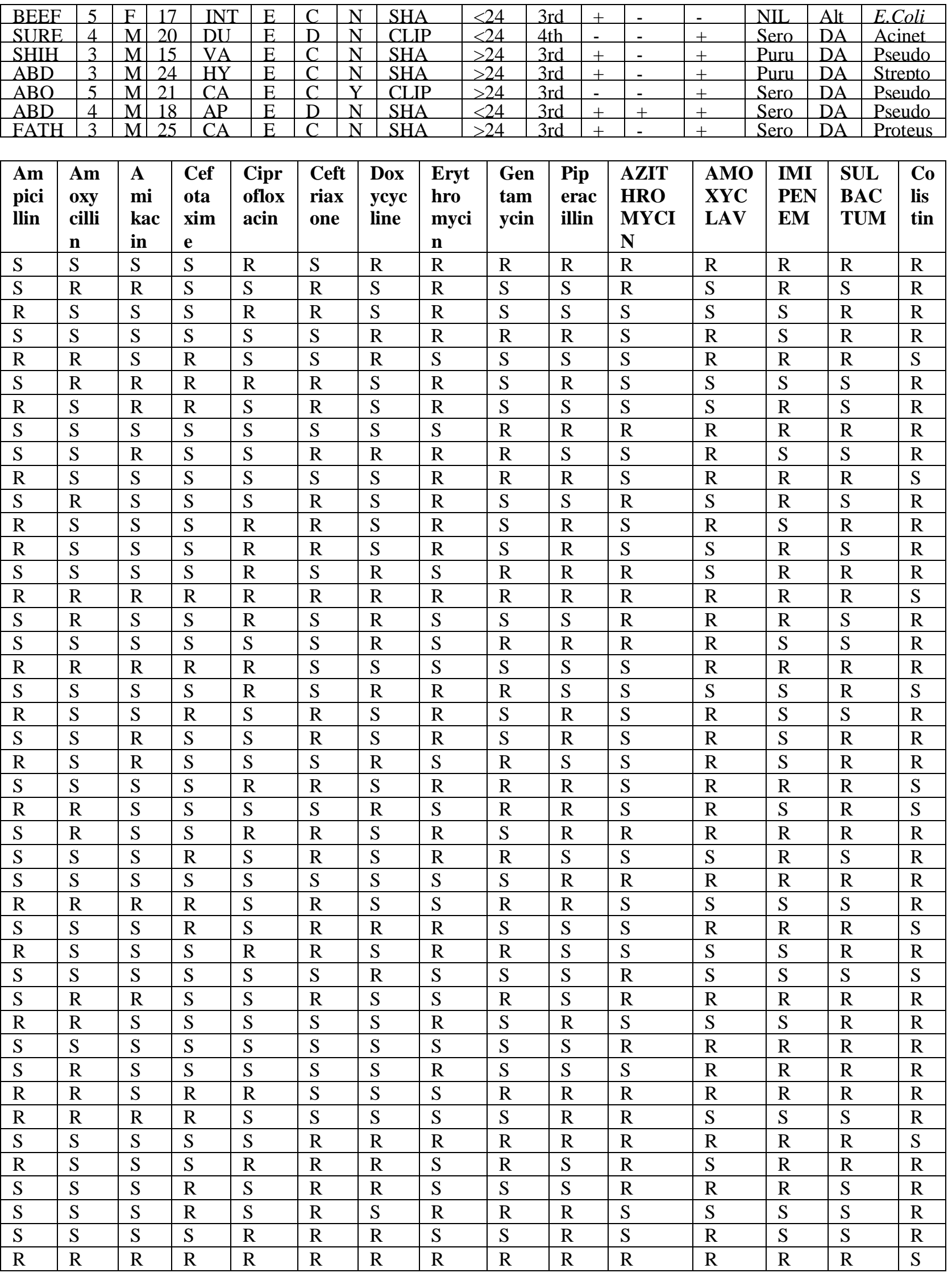




\begin{tabular}{|c|c|c|c|c|c|c|c|c|c|c|c|c|c|c|}
\hline$S$ & $S$ & $S$ & $\mathrm{R}$ & $\mathrm{R}$ & $\mathrm{R}$ & $\mathrm{R}$ & $\mathrm{R}$ & $S$ & $\mathrm{R}$ & $S$ & $S$ & $\mathrm{R}$ & $\mathrm{S}$ & $\mathrm{R}$ \\
\hline$S$ & $\mathrm{~S}$ & S & $S$ & $\mathrm{R}$ & $\mathrm{R}$ & $\mathrm{R}$ & $\mathrm{R}$ & S & $\mathrm{S}$ & $\mathrm{S}$ & $\mathrm{R}$ & $\mathrm{R}$ & $\mathrm{S}$ & $\mathrm{R}$ \\
\hline$R$ & $S$ & $S$ & $\mathrm{R}$ & $S$ & $\mathrm{R}$ & $S$ & $S$ & $\mathrm{R}$ & $\mathrm{S}$ & $\mathrm{R}$ & $\mathrm{R}$ & $S$ & $S$ & $S$ \\
\hline $\mathrm{S}$ & $\mathrm{S}$ & $\mathrm{S}$ & $\mathrm{R}$ & $\mathrm{R}$ & $\mathrm{R}$ & $\mathrm{R}$ & $\mathrm{S}$ & $S$ & $S$ & $\mathrm{R}$ & $\mathrm{R}$ & $\mathrm{R}$ & $\mathrm{S}$ & $\mathrm{R}$ \\
\hline $\mathrm{S}$ & $\mathrm{S}$ & $\mathrm{S}$ & $\mathrm{S}$ & $\mathrm{R}$ & $\mathrm{R}$ & $\mathrm{R}$ & $\mathrm{S}$ & $\mathrm{S}$ & $\mathrm{S}$ & $\mathrm{S}$ & $\mathrm{S}$ & $\mathrm{S}$ & $\mathrm{R}$ & $\mathrm{R}$ \\
\hline $\mathrm{R}$ & $\mathrm{R}$ & $\mathrm{R}$ & $\mathrm{R}$ & $\mathrm{R}$ & $\mathrm{S}$ & $S$ & $S$ & $S$ & $\mathrm{R}$ & $\mathrm{R}$ & $\mathrm{R}$ & $\mathrm{R}$ & $\mathrm{R}$ & $\mathrm{R}$ \\
\hline $\mathrm{R}$ & $S$ & $S$ & $S$ & $\mathrm{R}$ & $\mathrm{S}$ & $\mathrm{R}$ & $\mathrm{R}$ & $S$ & $S$ & $\mathrm{R}$ & $S$ & $\mathrm{R}$ & $\mathrm{R}$ & $\mathrm{R}$ \\
\hline $\mathrm{R}$ & $S$ & $S$ & $S$ & $S$ & $\mathrm{R}$ & $S$ & $\mathrm{~S}$ & $\mathrm{R}$ & $\mathrm{S}$ & $\mathrm{R}$ & $S$ & $\mathrm{R}$ & $\mathrm{R}$ & $\mathrm{R}$ \\
\hline$S$ & $S$ & $S$ & $S$ & $\mathrm{R}$ & $\mathrm{R}$ & $\mathrm{R}$ & $S$ & $\mathrm{R}$ & $\mathrm{S}$ & $\mathrm{R}$ & $\mathrm{R}$ & $\mathrm{R}$ & $\mathrm{R}$ & $\mathrm{R}$ \\
\hline $\mathrm{S}$ & $S$ & $S$ & $\mathrm{~S}$ & $S$ & $\mathrm{~S}$ & $S$ & $S$ & $\mathrm{R}$ & $\mathrm{R}$ & $\mathrm{R}$ & $\mathrm{R}$ & $\mathrm{R}$ & $\mathrm{R}$ & $\mathrm{R}$ \\
\hline$S$ & $S$ & $S$ & $\mathrm{R}$ & $\mathrm{R}$ & $\mathrm{S}$ & $\mathrm{R}$ & $\mathrm{R}$ & $\mathrm{R}$ & $S$ & $S$ & $S$ & $\mathrm{R}$ & $\mathrm{S}$ & $S$ \\
\hline $\mathrm{R}$ & $\mathrm{R}$ & $S$ & $S$ & $\mathrm{R}$ & $\mathrm{S}$ & $\mathrm{R}$ & $\mathrm{S}$ & $\mathrm{R}$ & $S$ & $\mathrm{R}$ & $S$ & $\mathrm{R}$ & $\mathrm{S}$ & $\mathrm{R}$ \\
\hline $\mathrm{S}$ & $S$ & $S$ & $S$ & $\mathrm{R}$ & $\mathrm{R}$ & $\mathrm{R}$ & $\mathrm{S}$ & $\mathrm{R}$ & $\mathrm{R}$ & $S$ & $\mathrm{R}$ & $\mathrm{R}$ & $S$ & $\mathrm{R}$ \\
\hline $\mathrm{R}$ & $S$ & $S$ & $\mathrm{R}$ & $\mathrm{S}$ & $\mathrm{R}$ & $S$ & $\mathrm{R}$ & $S$ & $\mathrm{R}$ & $S$ & $\mathrm{R}$ & $S$ & $\mathrm{R}$ & $\mathrm{R}$ \\
\hline $\mathrm{R}$ & $\mathrm{R}$ & $\mathrm{S}$ & $\mathrm{R}$ & $S$ & $\mathrm{R}$ & $\mathrm{R}$ & $\mathrm{R}$ & $S$ & $S$ & $S$ & $S$ & $S$ & $S$ & $S$ \\
\hline $\mathrm{S}$ & $S$ & $S$ & $\mathrm{R}$ & $\mathrm{R}$ & $\mathrm{R}$ & 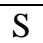 & $\mathrm{S}$ & $\mathrm{R}$ & $S$ & $\mathrm{~S}$ & $S$ & $S$ & $S$ & $\mathrm{~S}$ \\
\hline $\mathrm{R}$ & $\mathrm{R}$ & $S$ & $\mathrm{R}$ & $S$ & $\mathrm{~S}$ & $\mathrm{R}$ & $\mathrm{S}$ & $\mathrm{R}$ & $S$ & $\mathrm{~S}$ & $\mathrm{~S}$ & $\mathrm{~S}$ & $S$ & $\mathrm{~S}$ \\
\hline $\mathrm{S}$ & $S$ & $S$ & $S$ & $\mathrm{~S}$ & $\mathrm{R}$ & $\mathrm{R}$ & $\mathrm{R}$ & $S$ & $\mathrm{R}$ & $\mathrm{R}$ & $S$ & $S$ & $S$ & $\mathrm{R}$ \\
\hline$S$ & $\mathrm{R}$ & $S$ & $\mathrm{R}$ & $\mathrm{R}$ & $\mathrm{R}$ & $\bar{S}$ & $\mathrm{~S}$ & $S$ & $S$ & $\mathrm{~S}$ & $S$ & $\mathrm{R}$ & $S$ & $\mathrm{R}$ \\
\hline$S$ & $S$ & $S$ & $S$ & $\mathrm{R}$ & $\mathrm{S}$ & $S$ & $\mathrm{R}$ & $S$ & $S$ & $\mathrm{R}$ & $\mathrm{R}$ & $\mathrm{R}$ & $S$ & $\mathrm{R}$ \\
\hline $\mathrm{S}$ & $S$ & $S$ & $\mathrm{R}$ & $S$ & $\mathrm{R}$ & $\mathrm{S}$ & $\mathrm{S}$ & $\mathrm{R}$ & $\mathrm{R}$ & $\mathrm{S}$ & $S$ & $S$ & $\mathrm{R}$ & $\mathrm{R}$ \\
\hline $\mathrm{R}$ & $\mathrm{R}$ & $\mathrm{R}$ & $\mathrm{R}$ & $\mathrm{R}$ & $\mathrm{R}$ & $\mathrm{R}$ & $\mathrm{R}$ & $\mathrm{R}$ & $\mathrm{R}$ & $\bar{R}$ & $\mathrm{R}$ & $\mathrm{R}$ & $\mathrm{R}$ & $\mathrm{S}$ \\
\hline $\mathrm{R}$ & $\mathrm{S}$ & $\mathrm{S}$ & $\mathrm{S}$ & $\mathrm{R}$ & $\mathrm{R}$ & $S$ & $\mathrm{R}$ & $S$ & $\mathrm{~S}$ & $\mathrm{R}$ & $\mathrm{R}$ & $\mathrm{R}$ & $\mathrm{R}$ & $\mathrm{R}$ \\
\hline $\mathrm{R}$ & $S$ & $\mathrm{~S}$ & $S$ & $S$ & $\mathrm{R}$ & $\mathrm{R}$ & $\mathrm{R}$ & $S$ & $\mathrm{~S}$ & $\mathrm{~S}$ & $\mathrm{R}$ & $\mathrm{R}$ & $\mathrm{R}$ & $\mathrm{R}$ \\
\hline $\mathrm{R}$ & $S$ & $S$ & $\mathrm{R}$ & $\mathrm{R}$ & $\mathrm{S}$ & $\mathrm{S}$ & $\bar{R}$ & $S$ & $\mathrm{R}$ & $\mathrm{S}$ & $\mathrm{R}$ & $\mathrm{S}$ & $\mathrm{R}$ & $\mathrm{S}$ \\
\hline$S$ & $\mathrm{~S}$ & $\mathrm{~S}$ & $S$ & $\mathrm{R}$ & $\mathrm{R}$ & $\mathrm{R}$ & $\mathrm{S}$ & $\mathrm{R}$ & $\mathrm{R}$ & $\mathrm{S}$ & $\mathrm{R}$ & $\mathrm{R}$ & $\mathrm{R}$ & $\mathrm{S}$ \\
\hline $\mathrm{S}$ & $\mathrm{S}$ & $\mathrm{S}$ & $\mathrm{R}$ & $\mathrm{S}$ & $\mathrm{R}$ & $\mathrm{S}$ & $\mathrm{S}$ & $\mathrm{R}$ & $\mathrm{R}$ & $\mathrm{S}$ & $\mathrm{S}$ & $\mathrm{S}$ & $\mathrm{R}$ & $\mathrm{R}$ \\
\hline
\end{tabular}

\section{Summary:-}

* Postoperative wound infection is more common in emergency case.

* Most of the patients had undergone surgery which is classified as clean contaminated

* Very few patients not received preoperative antibiotic prophylaxis

* Very few patients had preoperative bath

* Most of patients were prepared $>24$ hrs before surgery and hair removal was done by shaving.

- Pseudomonas is the most common organism cultured

* Amikacin is the most sensitive antibiotic and colistin was the most resistant antibiotic.

Bibliography:-

1. AnthonyT,MurrayBW,Sum-PingJT,etal.Evaluatinganevidence-basedbundlefo rpreventingsurgicalsiteinfection:arandomizedtrial.ArchSurg.2011;146(3):263- 269.

2. AwadSS.Adherencetosurgicalcareimprovementprojectmeasuresandpost-opera tivesurgicalsiteinfections.SurgInfect(Larchmt).2012;13(4):234-237.

3. AwadSS,PalacioCH,SubramanianA,etal.Implementationofamethicillin-resista ntStaphylococcusaureus(MRSA)preventionbundleresultsindecreasedMRSAsu rgicalsiteinfections. AmJSuG. 2009;198(5):607-610.

4. AragonD,SoleML.ImplementingbestpracticestrategiestopreventinfectionintheI CU.CritCareNursClinNorthAm.2006;18(4):441-452.

5. BessesenMT,LopezK,GuerinK,etal.Comparisonofcontrolstrategiesformethicilli n-resistant Staphlococcusaureus.AmJInfectControl.2013;41(11):1048-1052.

6. BullA, WilsonJ, WorthLJ,etal.Abundleofcaretoreducecolorectalsurgicalinfectio ns:anAustralianexperience.JHospInfect.2011;78(4):297-301.

7. CaseyAL,ElliotTS.Progressinthepreventionofsurgicalsiteinfection.CurrOpinIn fectDis.2009;22(4):370-375.

8. CimaR,DankbarE,LovelyJ,etal.Colorectalsurgerysurgicalsiteinfectionreductio 
nprogram:anationalsurgicalqualityimprovementprogram-

drivenmultidisciplinarysingle-institutionexperience.JAmCollSurg. 2013;216(1):23-33.

9. CrawfordT,RodvoldKA,SolomkinJS.Vancomycinforsurgicalprophylaxis.Clin InfectDis.2012;54(10):1474-1479.

10. CrollaRM,vanderLaanL,VeenEJ,HendriksY,vanSchendelC,KluytmansJ.Redu ctionofsurgicalsiteinfectionsafterimplementationofabundleofcare.PloSOne.20 12;7(9):e44599.

11. DyrkornOA,KristoffersenM,WalbergM.Reducingpost-caesareansurgicalwoun dinfectionrate:animprovementprojectinaNorwegianmaternityclinic.BMJQualS af.2012;21(1):206-210.

12. EdmistonCE,DaoudFC.Isthereanevidence-basedargumentforembracingananti microbial(triclosan)-coatedsuturetechnologytoreducetheriskforsurgical-siteinfe ctions?:Ameta-analysis.Surgery.

13. GrafK,SohrD,HaverichA,KühnC,GastmeierP,ChabernyIF.Decreaseofdeepster nalsurgicalsiteinfectionratesaftercardiacsurgerybyacomprehensiveinfectionco ntrolprogram.InteractCardiovascThoracSurg.2009;9(2):282-286.

14. HumphreysH.Preventingsurgicalsiteinfection. Wherenow?JHospInfect.2009;73 (4):316-322.

15. JainM,MillerL,BeltD,KingD,BerwickDM.DeclineinICUadverseevents, nosoc omialinfectionsandcostthroughaqualityimprovementinitiativefocusingonteam workandculturechange.QualSafHealthCare. 2006;15(4):235-239.

16. KramerA,SchillingM,HeideckeCD.Infectionpreventioncheck-inandinfection preventioncheck-outtopreventnosocomialinfections.ZentralblChir.2010;135 (1):44-48.

17. LavuH,KlingeMJ,NowcidLJ,etal.Perioperativesurgicalcarebundlereducespa ncreaticoduodenectomywoundinfections.JSurgRes.2012;174(2):215-221.

18. LeaperDJ,TannerJ,KiernanM,AssadianO,EdmistonCE.Surgicalsiteinfection: poorcompliancewithguidelinesandcarebundles.IntWoundJ.2014.Epubaheado fprint.February25,2014.Availableat:http://onlinelibrary.wiley.com.Accessed October8,2014.

19. LiauKH,AungKT,ChuaN, etal.Outcomeofastrategytoreducesurgicalsiteinfecti oninatertiary-carehospital.SurgInfect(Larchmt).2010;11(2):151-159.

20. MisteliH,WidmerAF,WeberWP, etal.Successfulimplementationofawindowfo rroutineantimicrobialprophylaxisshorterthanthatoftheWorldHealthOrganizati onstandard.InfectControlHosp Epidemiol. 2012;33(9):912-916.

21. ParsonsD,BreenJ.Acolorectal-carebundlelltoreducesurgicalsiteinfectionsinco lorectalsurgeries:asingle-centerexperience.PermJ.2012;16(3):10-16.

22. PittalisS,FerraroF,PuroV.Abundleofcaretoreducecolorectalsurgicalinfections

23. :anAustralianexperience.Isittherealrevolution?JHospInfect.2012;80(1):93-94

24. ,authorreply95.

25. RyckmanFC,SchoettkerPJ,HaysKR,etal.Reducingsurgicalsiteinfectionsatape diatricacademicmedicalcenter.JtCommJQualPatientSaf.2009;35(4):192-198.

26. SchweizerM,PerencevichE,McDanielJ,etal.Effectivenessofabundledinterven tionofdecolonizationandprophylaxistodecreaseGrampositivesurgicalsiteinfec tionsaftercardiacororthopedicsurgery:systematicreviewandmeta-analysis.BM J.2013;346:f2743.

27. SchwulstSJ,MazuskiJE.Surgicalprophylaxisandothercomplicationavoidance carebundles.SurgClinNorthAm.2012;92(2):285-305,ix.

28. SydnorER,PerlTM.Hospitalepidemiologyandinfectioncontrolinacute-careset tings.ClinMicrobiolRev. 2011;24(1):141-173.

29. TillmanM,Wehbe-JanekH,HodgesB,SmytheWR,PapaconstantinouHT.Surgi calcareimprovementprojectandsurgicalsiteinfections:canintegrationinthesurg icalsafetychecklistimprovequalityperformanceandclinicaloutcomes?JSurgRe s.2013;184(1):150-156.

30. ThompsonKM,OldenburgWA,DeschampsC,RuppWC,SmithCD.Chasingzero

31. :thedrivetoeliminatesurgicalsiteinfections.AnnSurg.2011;254(3):430-436, disc ussion436-437.

32. UçkayI,HarbarthS,PeterR,LewD,HoffmeyerP,PittetD.Preventingsurgicalsitei nfections.ExpertRevAntiInfectTher.2010;8(6):657-670.

33. vanderSlegtJ,vanderLaanL,VeenEJ,HendriksY,RommeJ,KluytmansJ.Implem entationofabundleofcaretoreducesurgicalsiteinfectionsinpatientsundergoingv ascularsurgery.PloSOne.2013;8(8):e71566.

34. WaitsSA,FritzeD,BanerjeeM,etal.Developinganargumentforbundledintervent ionstoreducesurgicalsiteinfectionincolorectalsurgery.Surgery.2014;155(4):60 2-606. 
35. Robert G Sawyer and Timothy L Pruett. Wound infection. Surgical Clinics ofNorth America 1994 June; 74 (3): 519-536.

36. Claesson BEB, Holmlund DEW. Predictors of intraoperative bacterial contamination and postoperative infection in elective colorectal surgery. J.Hosp Infect 1988; 11:127.

37. Cruse PJE, Foord RA. Five-year prospective study of 23, 649 surgical

38. wounds. Arch Surg 1973; 107: 206

39. Cruse PJE, Foord R. The epidemiology of wound infection: A 10 year

40. prospective study of 62,939 wounds. Surg Clin North Am 1980; 60: 27.

41. Davidson AIG, Clark C, Smith G. Postoperative wound infection: A computer

42. Analysis. Br J Surg 1971; 58: 33.

43. Mead PB, Pories SE, Hall P. Decreasing the incidence of surgical wound

44. infections. Arch Surg 1986; 121: 458.

45. Ehrenkranz NJ. Surgical wound infection occurrence in clean operations: Risk stratification for interhospital comparisons. Am J Med 1981; 70: 909.

46. Gil-Egea MJ, Pi-Sunyer MT, Verdaguer A. Surgical wound infections. Prospective study of 4,468 clean wounds. Infect Control Hosp Epidemiol 1987; 8: 277.

47. Haley RW, Culver DH, Morgan WM. Identifying patients at high risk of

48. surgical wound infection. Am J Epidemiol 121:206, 1985.

49. Nagachinta T, Stephens M, Reitz B. Risk factors for surgical-wound infection

50. following cardiac surgery. J Infect Dis 1987; 156: 967.

51. Culver DH, Horan TC, Gaynes RP. Surgical wound infection rates by wound class, operative procedure, and patient risk index. Am J Med 1991; 91 (Suppl 3B): 152S.

52. Garibaldi RA, Cushing D, Lerer T. Risk factors for postoperative infection. An J Med 1991; 91(Suppl 3B): 158S

53. Lewis RT. Wound infection after gastroduodenal operations: A 10year review. Can J Surg 1977; 20: 435.

54. Edwards LD. The epidemiology of 2056 remote site infections and 1966 surgical wound infections occurring in 1865 patients: A four year study of 40,923 operations at Rush Presbyterian-St. Luke's Hospital, Chicago. Ann Surg 1976; 184:758.

55. Rhoads JE, Alexander CE. Nutritional problems of surgical patients Ann NY

56. Acad Sci 1955; 63:268.

57. Shukla VK, Roy SK, Kumar J, et al. Correlation of immune and nutritional status with wound complications in patients undergoing abdominal surgery. Am Surg 1985; 51: 442.

58. Gorse GJ, Messner RL, Stephens ND. Association of malnutrition with

59. nosocomial infection. In fect Control Hosp Epidemiol 1989; 10: 194.

60. Shapiro M, Munoz A, Tager IB. Risk factors for infection at the operative site

61. after abdominal or vaginal hysterectomy. N Engl J Med 1982; 307: 1661

62. Whyte $\mathrm{W}$, Hambreaeus A, Laurell G. The relative importance of the routes and sources of wound contamination during general surgery: I. Non-airborne. J Hosp Infect 1991; 18: 93.

63. Condon RE, Schulte WJ, Malangoni MA. Effectiveness of a surgical wound

64. infection program. Arch Surg 1983; 118: 303.

65. Ayliffe GAJ. Role of the environment of the operating suite in surgical wound

66. infection. Rev Infect Dis 1991; 13 (Supl 10): S 800.

67. Whyte W, Hambraeus A, Laurell G. The relative importance of the routes and sources of wound contamination during general surgery: II. Airborne. J Hosp Infect 1992; 22: 41.

68. Whyte W, Hodgson R, Tinkler J. The importance of airborne contamination of

69. wounds. J Hosp Infect 1982; 3: 123.

70. Lidwell OM, Elson RA, Lowbury EJL. Ultraclean air and antibiotics for

71. prevention of post-operative infection. Acta Orthop Scand 1987; 58: 4.

72. Seropian R, Reynolds BM. Wound infections after preoperative depilatory

73. versus razor preparation. Am J Surg 1971; 121: 251. 